\title{
Escenario para el desarrollo de línea de productos financieros verdes en la economía colombiana
}

\section{The scenario for the development of green financing products in the Colombian economy}

\author{
Daniela Rua Usme a, Adriana María Ospina b , Catalina Ramírez López c, Paola Ortiz ${ }^{\mathrm{d}}$ \& \\ Julián Alberto Patiño-Murillo e,f \\ a Institución Universitaria ESUMER, Medellín, Colombia. danielarua.09111@gmail.com \\ b Institución Universitaria ESUMER, Medellín, Colombia. eilyn45@hotmail.com \\ c Institución Universitaria ESUMER, Medellín, Colombia. catartica13@gmail.com \\ d Institución Universitaria Pascual Bravo, Medellín, Colombia.paola.ortiz@pascualbravo.edu.co \\ e Institución Universitaria Pascual Bravo, Medellín, Colombia. julian.patino@pascualbravo.edu.co \\ ${ }^{f}$ Red Tecnoparque Colombia SENA, Medellín, Colombia.
}

Recibido: septiembre 17, 2019. Aceptado: diciembre 15, 2019.

\section{Resumen}

Con el presente trabajo investigativo se pretende proponer a la banca colombiana, la apertura de una nueva línea de negocio enfocada a ofrecer productos con inversión y destinación ecológica, lo que conlleva a entender la importancia que tienen los proyectos verdes en el mundo actual, y como se podrían ver beneficiados con el apoyo a esta iniciativa, en temas de disminución de impuestos por la labor social que se desarrollaría. Lo anterior se logrará a través de la implementación de estrategias, cuya finalidad sea la captación de dinero de pequeños y grandes inversionistas, mediante la emisión de bonos verdes, los cuales generarían una tasa de interés más alta de la que se ofrece en el mercado convencional por productos similares, dichos recursos tendrán una destinación amigable con el medio ambiente. Cuando se habla de la destinación amigable de recursos, se hace foco a la creación de una nueva línea de crédito que se oriente hacia el desarrollo de las finanzas verdes, donde la tasa de colocación sea más baja con relación a las demás líneas de crédito y así las personas se interesen en adquirir y apoyar este tipo de iniciativas sostenibles. Este trabajo describe las características de los productos verdes, su clasificación y principales características, para luego presentar algunos ejemplos de corporaciones financieras que ofrecen Líneas de crédito verdes en Colombia.

Palabras Clave: bonos verdes, mercado del carbono, finanzas verdes, sostenibilidad.

\begin{abstract}
This research work intends to propose to Colombian banks, the opening of a new line of business focused on offering products with investment and ecological destination. These "green" financial products lead us to understand the importance of green projects in today's world, and how they could benefit from supporting this initiative, in terms of tax reduction for the social work that would be developed. This goal will be achieved through the implementation of strategies, whose purpose is to raise money from small and large investors, through the issuance of green bonds, which would generate a higher interest rate than that offered in the conventional market for similar products, these resources will have an environment-friendly destination. When talking about the friendly destination of resources, the focus is on the creation of a new line of credit that geared towards the development of green finance. In this line, the placement rate is lower concerning the other lines of credit, and people could be more interested in acquiring and supporting this type of sustainable initiatives. This paper describes the characteristics of green products, their classification, and main characteristics, and then presents some examples of financial corporations that offer Green Credit Lines in Colombia.
\end{abstract}

Keywords: Green bonds, Carbon market, green finances, sustainability.

\section{INTRODUCCIÓN}

El tema de los bonos verdes es una iniciativa innovadora en un ecosistema económico empresarial ávido por nuevos productos y soluciones [1], la cual ha generado impactos positivos a nivel mundial desde la primera

\section{Citar como:}

Daniela Rua Usme, Adriana María Ospina, Catalina Ramírez López, Paola Ortiz \& Julián Alberto Patiño-Murillo. "Escenario para el desarrollo de línea de productos financieros verdes en la economía colombiana" Revista CINTEX, Vol. 24(2), pp. 64-90. 2019. 
emisión que se realizó en el año 2006, por el banco Europeo de inversiones, y aunque en un principio fue difícil la promulgación de este tipo de propuestas ecológicas y aún más el apoyo por parte de las grandes entidades, hoy en día tiene una gran acogida por parte de organizaciones que están de lado del desarrollo sostenible [2], [3].

Para nadie es un secreto el estado actual del medio ambiente y de cómo nuestros hábitos de consumo excesivos e industrialización desmedida, están acabando con los recursos naturales del planeta, un tema preocupante para unos y de poco interés para otros [4]. Algo relevante, es que Colombia se ha sumado a este tipo de iniciativas, y le apuesta al futuro del medio ambiente; es por ello que entidades como Bancolombia, Davivienda, Celsia y Bancóldex, han hecho un gigantesco aporte a la naturaleza y esto se ha logrado mediante la emisión de bonos verdes, los cuales tienen una finalidad clara y concisa y es la de incentivar los proyectos ecológicos como lo son: las energías renovables, la eficiencia energética, la construcción sostenible, el transporte sostenible, el control de la contaminación, el ecoturismo y eficiencia en el uso de los recursos [5].

Aunque ya se han dado los primeros pasos, se considera importante aumentar la inclusión de otras entidades colombianas a este tipo de proyectos sostenibles, dado que el cambio climático es un tema que nos toca a todos [6].

Por lo anterior, surgen iniciativas en donde la banca colombiana será el principal protagonista y esto se dará básicamente a través de propuestas para la creación de nuevas líneas de Créditos verdes, en donde se cuenta con la contribución de dos roles importantes: aquellos que aportan el flujo de capital y los "agentes" que le dan una finalidad de inversión que contribuye con el entorno ambiental.

El primer factor básicamente sería la captación de dinero para iniciativas "verdes", lo que constituye la idea que se viene desarrollando desde el principio de las actividades bancarias en este sentido [7], y es aquí donde surge el interrogante: ¿Cómo puede el sector bancario colombiano relacionarse con esta temática? La respuesta es puede ser más sencilla de lo que parece, y es aquí donde se pretende realizar una contribución con este trabajo, para que se difunda la información disponible acerca de estos productos financieros "verdes" y las entidades bancarias emitan más bonos verdes de los que se han emitido en Colombia actualmente. Es esencial que la banca tradicional adopte este tipo de iniciativas y propuestas, pues este tipo de entidades servirían como la principal garantía de que la inversión en bonos ecológicos es segura porque son entes calificados y cuentan con todas las seguridades respectivas para el manejo de los recursos; el papel que desempeñan los bancos está orientado a las captaciones de dinero, las cuales serán utilizadas más como una medida ambiental que como una acción lucrativa para ellos, por lo que se plantea el incremento de las tasas de interés para las inversiones realizadas en bonos verdes, lo que se convertiría en una opción atractiva para aquellas personas o compañías que quieren diversificar e innovar en sus portafolios de inversión y al mismo tiempo contribuir con las finanzas sostenibles.

El segundo factor tiene que ver con la creación de líneas de crédito verdes orientadas a la financiación de proyectos sostenibles, los cuales contribuyen de gran manera al desarrollo económico del país, pero de una forma más consciente con el planeta. En este punto lo que se busca es que los bancos analicen y acepten la opción de disminuir las tasas de interés de los créditos destinados para éste fin, permitiendo así, que las personas que tengan buenas iniciativas en pro del medio ambiente cuenten con ese flujo de dinero para llevar a cabo sus ideas de negocio; ésta iniciativa no va enfocada únicamente a las personas del común, pues el alcance de esta propuesta debe llegar hasta las empresas industrializadas, que en estos momentos son las que más contribuyen al daño ambiental.

Las entidades bancarias que se interesen en cumplir un plan de desarrollo sostenible mediante los créditos verdes que otorguen, se podrían ver incentivadas con beneficios tributarios, mayor acogida de inversionistas, ampliación de su portafolio de servicios y, algo no menos importante, sería la buena reputación que conseguirían por el apoyo a proyectos innovadores que se esmeran por mejorar la economía del país.

\section{ANTECEDENTES}

El planeta Tierra es un cuerpo celeste que cuenta con una superficie terrestre dividida en capas tectónicas, este planeta fue formado hace más de 4550 millones de años y ocupa el tercer lugar en el sistema solar. Desde el punto de vista de la ciencias naturales esta es una definición válida, pero el planeta no es solo una estrella más situada en el espacio, también hacen parte de la tierra todos y cada uno de los seres vivos que habitan este lugar, y que encuentran en el planeta las condiciones necesarias para la subsistencia; a pesar de esto, el ser humano en general ha demostrado carecer de un sentido de pertenencia por el planeta y los recursos que ofrece, pues comportamientos como el consumismo excesivo, las malas prácticas empresariales [8] y la ambición monetaria ponen en peligro el balance y la continuidad de la existencia del planeta. 66 
Desafortunadamente, estas tendencias generan una explotación continua de los recursos naturales, a un ritmo acelerado que está generando de a poco su destrucción y ante tanto abuso, ya se están mostrando las primeras señales de alarma, a través de fenómenos como el Calentamiento global.

El Calentamiento Global denomina a la tendencia al incremento que ha mostrado la temperatura global del planeta Tierra a través de los últimos 150, comportamiento usualmente atribuido al impacto de la contaminación por la actividad humana, y específicamente a la quema de combustibles fósiles como el carbón y el petróleo, y a la tala indiscriminada de bosques. Acciones como estas, están generando mayores impactos negativos en el ambiente.

Ante tal situación, muchos países han tomado conciencia, por lo cual se han implementado nuevas estrategias que permitan obtener un desarrollo, pero de una manera sostenible [9]; es decir, es posible fortalecer las economías de los países de una forma responsable con el medio ambiente y un ejemplo claro de estas iniciativas son la emisión de bonos verdes, la generación de energías renovables, los impuestos verdes, el ecoturismo, el transporte limpio, entre otros. Ideas innovadoras que mejoran la situación del planeta [10], por lo cual es relevante mencionar algunos antecedentes y más aún si se habla sobre escenarios y propuestas para la apertura de una línea de productos financieros verdes en la banca colombiana.

En este sentido, se empezará hablando sobre "El Mercado de los Bonos de Carbono (bonos verdes): Una revisión", artículo publicado en la Revista Interamericana de Ambiente y Turismo en agosto del año 2005, desarrollado por Germán Lobos, Oscar Vallejos, César Caroca, y Cristián Marchant [11]. Es un artículo en el que los autores analizan la situación ambiental y cómo ven la problemática de emisión de gases de efecto invernadero, desde un punto no solo ecológico sino también como una oportunidad de inversión de los países industrializados en países en vía de desarrollo como Colombia. Dicha propuesta nace a partir del protocolo de Kioto, el cual tiene una finalidad específica y es la de incentivar la reducción de emisión de GEI por parte de los países más contaminantes (los industrializados), con el objetivo de mitigar los impactos generados por los cambios climáticos. Para poner en marcha la iniciativa se tiene planteados, como mecanismos de acción, la forestación y reforestación, los cuales son proyectos sostenibles que necesitan de un financiamiento costoso y más aún si lo hablamos desde un país desarrollado, en el cual la producción y el consumo excesivo es su fuente de ingreso más grande y a la vez la que más impactos negativos le trae al planeta. Esa es la razón por la que se ven en la necesidad de crear medios de inversiones que se puedan llevar a cabo en países Subdesarrollados, creando así el primer bono verde en el año 2006, en el cual lo que se hace básicamente, es captar recursos de empresas públicas o privadas y destinar ese dinero para apoyar proyectos amigables con el medio ambiente, a cambio de recibir unos intereses por su inversión y la devolución del capital según negociaciones pactadas, además de recibir certificados de reducción de GEI (Gases de Efecto Invernadero). Algo relevante del artículo en cuestión, que permite ponerlo como una referencia de antecedentes, es como el hecho de que siendo una publicación que cuenta con más de 12 años, ayuda a dimensionar la problemática del cambio climático que se vive a través del tiempo, además permite observar y analizar la acogida y aceptación de los bonos verdes, para contribuir con el modelo desarrollo limpio planteado en el protocolo Kioto [11].

Además de la contribución que están realizando los países desarrollados para mitigar los impactos generados por la emisión de gases de Efecto invernadero, cabe resaltar la labor impulsada por España, en donde ven los bonos verdes como una alternativa para financiar los proyectos sostenibles, tomando como ejemplo "Valoración de instrumentos emergentes de financiación: Bonos verdes", el cual es un trabajo de grado, desarrollado por Mohamed Yacine El Morjani, de la universidad politécnica de Valencia, España, en 2018 [12]. Este antecedente aborda el tema de finanzas verdes, pero desde la sostenibilidad innovadora, la cual se da través de cualquier plan, desarrollo o producto que tenga como propósito suavizar los efectos desfavorables del cambio climático o que, por el contrario, afiance los aspectos favorables. Por otra parte, otorga protagonismo a los bonos ecológicos como un producto financiero que permite apalancar proyectos ambientales y motivar a los inversores a hacer parte de la causa ecológica mediante su aporte. Adicionalmente, el documento de apoyo indica que, según la clasificación por sectores, más de la mitad de las emisiones de bonos verdes se dieron por parte del sector económico financiero y el $40 \%$ de proyectos verdes se han llevado a cabo en América. Todo lo expuesto en este trabajo es de interés común, debido a que se da una visión o referencia acerca de la posición que tienen las entidades financieras con el tema de bonos de carbono, sostenibilidad ambiental y a la vez da indicios acerca de los avances o retrasos que lleva Colombia en estos temas, respecto al continente americano.

La concientización y el cuidado del entorno debe partir desde cada persona, pero las empresas públicas y privadas deben cumplir un papel importante en esta labor, ya que son estas entidades las que más daños ambientales ocasionan, siendo importante destacar la contribución que ha realizado los bancos al tema de

Revista Cintex | Vol24(2) | julio-diciembre | 2019 
finanzas verdes, las cuales serán el principal actor, en la implementación de productos ecológicos en el caso de Colombia.

Para ello se toma como ejemplo los siguientes trabajos de grado y artículos de revista, los cuales tienen algo en común y eso es la aceptación de la Finanzas verdes por parte de las corporaciones bancarias, se empezará hablando sobre el "Análisis de viabilidad de la banca ética en España a través de Tríodos Bank. Comparativa económico-financiera con la banca tradicional" [13], artículo publicado en la revista de Estudios Cooperativos que habla sobre un nuevo banco en España llamado Tríodos Bank, se caracteriza por ser diferenciador de la banca tradicional debido a que su principal misión es ser un banco ético y transparente tanto a nivel de funcionamiento interno como externo, que genere rentabilidad, pero al mismo tiempo cuide el medio ambiente; busca realizar actividades de captación e inversión de fondos. Su propuesta de valor es que la banca vuelva a ser solidaria con el hábitat y con las personas. La nueva banca busca limitar préstamos que no tengan fines responsables con el ambiente y en cambio privilegiar a aquellos con proyecciones positivas, es decir, es consciente del papel que tiene como intermediario y su responsabilidad socioambiental al otorgar un crédito que cumpla con fines verdes. Mediante este antecedente se puede observar que ya existen entidades bancarias con productos financieros destinados a la sostenibilidad ambiental, por encima de la rentabilidad, lo que es una motivación para replicar este modelo en Colombia, dado que por medio de la investigación que se está efectuando, se quiere lograr sensibilizar a todos los actores que intervienen en las finanzas verdes. Siguiendo con los impactos positivos que están generando las corporaciones bancarias, es importante hablar sobre la huella financiera, por ello se menciona el antecedente "La banca y la sustentabilidad: Una aproximación teórica", artículo publicado en la revista Innovaciones de Negocios, por Ana Laura Sánchez y Felipe A. Pérez Sosa, en 2016 [14]. Artículo en el que se resalta la importancia que tiene la "Huella financiera", cuyo impacto es generado únicamente por el sector bancario y se trata de crear consciencia, de que su portafolio tiene consecuencias específicas, por ende, se debería generar una marca positiva. De acuerdo con esto, se reconoce que el desarrollo financiero debe ser simultáneo con el bienestar de las personas y del ambiente. A partir de la Huella Financiera, surge el concepto "la banca sostenible", la cual busca la inclusión social mediante una estrategia corporativa, orientada tanto a empleados de la misma compañía, como empresas no gubernamentales e incluso la sociedad en común, forjando su participación y cooperación mediante los proyectos de sustentabilidad, siendo estos, los aspectos esenciales para la toma de decisiones.

Algo a resaltar del artículo inmediatamente anterior, es el hecho de que la banca esté tomando el tema de finanzas verdes de una forma voluntaria, pues si bien, pueden haber incentivos detrás de los proyectos sostenibles, los intereses de las instituciones financieras, se basan en la minimización de riesgos, generar mayor patrimonio a los accionistas y otro no menos importante, es el hecho que hoy en día, los mismos clientes son los que exigen un portafolio más amplio que al mismo tiempo ayude al entorno en que nos movemos, es decir que sea algo recíproco [14].

Esto conlleva a hacer énfasis antecedente: "Alternativas para Incluir Aspectos Ambientales en el Sector Financiero" [15]. Con la idea de concientizar a los bancos sobre la importancia de las líneas de productos verdes en las entidades financieras latinoamericanas, dentro del proyecto "Ecobanking" del CLACDS (Centro Latinoamericano de Competitividad y Desarrollo Sostenible) se permitió que 5 funcionarios de la banca participaran como pasantes durante al menos 7 meses en bancos europeos con amplios conocimientos previos procesos de mejora de la pureza ambiental, buscando que la banca latinoamericana posea una perspectiva más clara de las implicaciones de un manejo ambiental responsable, tanto a nivel interno de los bancos, como en la evaluación del riesgo ambiental en general. De esta forma, se busca encontrar la manera en que las entidades financieras no solo con estos productos puedan mejorar los retos ambientales, también aprovechen las oportunidades de ingresos económicos que ofrece la inclusión de nuevos servicios, que además produce ventajas competitivas al posicionarse en mercados donde no hay mucha competencia, y mejora la reputación institucional al ser un banco amigable con el medio ambiente.

Adicional al importante papel desempeñado por las entidades bancarias, se quiere resaltar la labor desarrollada por una compañía española cuya visión la ha llevado a ser protagonista: "Los bonos verdes: el caso de Iberdrola" [16] es un trabajo de grado desarrollado por Juan Carlos Fernández Hinojosa, de la Universidad de Sevilla, España, en 2018. En él, se explica por qué son importantes los bonos verdes y se toma como referente la empresa lberdrola, la compañía más importante en el mercado de finanzas verdes en España; un grupo que se orienta a la creación de valor sostenible, compromiso social y respeto por el entorno, con orientación al cliente. El autor también analiza el mercado de bonos en general y la manera como el impulso a la inversión en proyectos limpios ayuda a recuperar el medio ambiente; así mismo, señala a los 
bonos verdes como un instrumento rentable no sólo para emisores o inversores, sino también para todo el planeta.

\subsection{ECO INNOVACIÓN PARA LAS PYMES}

Uno de los beneficiados en la financiación verde serían las empresas pymes, siempre y cuando centren su estrategia de crecimiento en la innovación sostenible para así tener crecimiento económico y ser competitivas en un mercado exigente como el de hoy. Los productos financieros verdes caen dentro de la línea de estrategias de Eco innovación, entendiendo este concepto como "cualquier cambio tanto en productos, como procesos, métodos o estructuras organizativas, cuya finalidad suponga un significativo y demostrable avance hacia el objetivo del desarrollo sostenible, ya sea mediante la reducción de impactos medioambientales o bien a través de un uso más eficiente y responsable de los recursos" [17]. Dado que la mayoría de las pymes tienen en el presente, problemas de financiamiento con la banca tradicional debido a los niveles de riesgo que riesgo que manejan, se busca incentivarlas para que a través de la incursión de las finanzas verdes encuentren una alternativa para aumentar los recursos con los que cuentan y focalicen sus esfuerzos en la creación de valor sostenible.

Son distintas las oportunidades de negocio que la eco innovación en la actualidad puede brindar a las pymes -transformación y/o elaboración de nuevos servicios, productos o tecnologías, mejoramiento de los procesos de producción o reconsideración del prototipo de negocio, a su vez, estas iniciativas pueden propiciar ahorros de costos y oportunidades adicionales de mercado, así como hacerlas más competitivas. Si bien la eco innovación puede estar sustentada en adelantos de tecnología, también puede estar impulsada por razones medioambientales (disminución de emisiones o recursos, por ejemplo) o por simples motivos económicos (como puede ser la introducción de productos ecológicos), pero con la gran diferencia de que produce siempre una mejora para el medio ambiente. Por lo anterior se quieren citar 3 antecedentes que muestran claramente la situación de las micro y pequeñas empresas a nivel de Antioquia, Colombia y América Latina, en temas de financiación.

En ese orden de ideas, se empezará hablando de las pequeñas empresas situadas en Antioquia, para lo cual se tiene un antecedente para profundizar un poco más en esta idea, "Análisis comparativo de las alternativas de financiación para las PYMES en Antioquia" [18], trabajo de grado desarrollado por Blanca Mery Gaviria Montoya, Jenny Leany Hincapié Vásquez y María Camila Bermeo Giraldo, de la Institución Universitaria Escolme (Medellín, Colombia, 2018). El Informe habla acerca de la forma actual más utilizada para el financiamiento de proyectos de las microempresas, que se llama microcrédito, como su nombre lo indica es un crédito de menor cuantía, lo cual genera menos riesgo para la entidad financiera que lo otorga, debido a que tiene características especiales como lo son: plan de pagos y cobro de cartera más reducidos en tiempo. La desventaja que tiene este tipo de crédito para los beneficiarios, radica en la tasa de interés, siendo más alta con respecto a otros tipos de crédito, debido a la inversión extra realizada por las corporaciones bancarias, ya que son créditos que manejan mayor operatividad, pues debe estudiar detalladamente al cliente mediante visitas a su negocio y como son considerados de alto riesgo, requiere mayor insistencia en el cobro de las cuotas del préstamo, cuando el cliente incluye en atrasos, incurriendo en el pago de la comisiones no justificadas. Los costos anteriores inciden en la tasa de interés que debe pagar el microempresario para que la entidad financiera se pueda sostener.

Lo que se busca mediante la propuesta de apertura de líneas de productos verdes en la banca Colombia, radica en ofrecer herramientas para que las microempresas tengan beneficios en temas de tasas de interés y oportunidades para sacar adelante su emprendimiento, pero a cambio se busca que éstas entidades se empoderen de proyectos que le sirvan a la sociedad y al medio ambiente, a través de ideas innovadoras, que sean visionarias y que tengan implementación tecnológica para que se vuelvan más competitivas en un entorno que está en constante cambio y que busca que los bancos fijen su mirada en éste tipo de nicho [18]. El principal desafío que tienen las pequeñas empresas en las principales ciudades de Colombia son las tasas de interés en temas de financiamiento, pero: ¿es este obstáculo una problemática generalizada en el país? Para responder este interrogante, los investigadores Eduardo Trujillo, Maribel Gamba y Laura Marcela Arenas Rojas realizaron una trabajo de grado para la Universidad Jorge Tadeo Lozano de Bogotá, titulado "Las dificultades de las Pymes en América Latina y Colombia para lograr ser competitivas y sostenibles" [19]. En dicha investigación, se brinda información acerca de la situación que deben afrontar actualmente las empresas pymes en Colombia, en donde se evidencia que un punto a trabajar es la competitividad, se indica que solo el $40 \%$ de estas instituciones tiene acceso a financiación por parte de las entidades financieras, debido a que los requisitos que deben cumplir para obtener un crédito son muy robustos, debido al riesgo que debe asumir el banco cuando realiza un otorgamiento de dinero, pues desafortunadamente son muy pocas las empresas pymes que logran sacar adelante su desarrollo de negocio. Estos hechos resaltan la necesidad

Revista Cintex | Vol24(2) | julio-diciembre | 2019 
de encontrar alternativas como la discutida en este trabajo, cuya finalidad está encaminada a fomentar la participación de las PYMES, en proyectos que serán financiados a través de la emisión de bonos verdes, en donde se utilice como medio, la innovación tecnológica y eficiente generando un menor impacto ambiental.

Mediante el planteamiento anterior, se logra identificar dos puntos que juegan en contra de las PYMES colombianas, a la hora de buscar alternativas de expansión y crecimiento del negocio, por lo cual se presume que la misma situación puede ser atravesada por otras Pymes en Latinoamérica. Para ello, se recogen los resultados de la investigación realizada por el grupo de profesores Felipe Salvador, Leal Medina, Roberto González y Bogar García de la Universidad Autónoma de Aguascalientes, en México, cuya finalidad era determinar qué tan informados están las micro y pequeñas empresas sobre la existencia de líneas de crédito sostenibles en el estado de Aguascalientes (México), para lo cual se utilizó como mecanismo una la encuesta de 67 empresas industriales, y donde solo el 4\% conocían este tipo de financiación [20].

La falta de sustentabilidad es una problemática que afecta el ámbito social, económico y cultural de una nación, y ante la gran preocupación de muchos países por mitigar los impactos que se puedan generar en dichos ámbitos, se han innovado con proyectos e iniciativas, siendo los créditos verdes un ejemplo de ellos, en las cuales las grandes empresas son las que se ven realmente beneficiadas. Sin embargo, ¿en dónde quedan las micro y pequeñas empresas? Son estas entidades las que requieren mayor ayuda, ya que en muchas ocasiones no cuentan con las garantías financieras que exige una banca comercial para la otorgación de créditos, y, adicionalmente, hay que resaltar que de las empresas manufactureras son las que más contaminación generan por los procesos productivos que manejan y al no contar con un equipo tecnológico que les ayude a estar a la vanguardia, se consumirán más recursos de lo que debería. Razón por la cual se considera importante proponer a los bancos la apertura de líneas de créditos verdes enfocadas a las micro y pequeñas empresas, además de ofrecerle servicios de consultoría, en donde se trabajará desde cerca con las necesidades que tenga cada empresa ya sea en medidas tecnológicas o con procesos de gestión y son precisamente puntos como estos, los que se quieren abordar en la propuesta de apertura de créditos sostenibles, fomentando de una manera responsable y colaborativa el desarrollo económico del país [20].

Además de la problemática de los microcréditos y las alternativas que juegan a favor o en contra de las PYMES, es importante hacer énfasis en el tema de sostenibilidad. El trabajo de Badii [21], señala que la sostenibilidad no requiere que la economía pierda dinamismo, pero manteniendo la diferenciación entre desarrollo y crecimiento. Se puede definir al crecimiento económico como la mejora de la calidad de vida que no implique un incremento del consumo de recursos, lo cual puede convertirlo en un fenómeno sustentable, e incluso deseable dentro de los objetivos primarios de las políticas de largo alcance. Es importante que esto se dé a conocer por medio del estudio en cuestión, porque es semejante al hecho de generar ganancias, pero de manera responsable con la naturaleza y la sociedad, cuando se habla de sostenibilidad es transcendental mencionar que existen 3 tipos:

- Una es la sostenibilidad ecológica que lo que busca es mantener a lo largo de los años un ecosistema donde puedan habitar las diferentes especies (animal, vegetal y humana).

- Sostenibilidad económica que no es más que hacer uso adecuado y eficiente de la riqueza natural para que permanezca el ciclo económico en la actualidad y en las generaciones venideras.

- Por último y no menos importante, la sostenibilidad social, que quiere fomentar el sentido de las conductas y valores en la sociedad para un mejor bienestar.

Es interesante combinar los tres aspectos porque todos ellos influyen en lo que se quiere lograr con los productos financieros verdes, que haya un cambio de mentalidad, en donde las industrias, las empresas y las personas estén alineadas hacia unos mismos objetivos, los cuales se basan en generar más ingresos y construir en un mejor planeta [21]. En este sentido, en el documento titulado "El nexo entre finanzas, sostenibilidad y energía", elaborado por Miguel Chamochín del Instituto Español de Estudios Estratégicos (2017) [22], se habla sobre los riegos que se puedan generar sobre los activos invertidos en combustible fósil, los cuales pueden llegar a ser denominados como "activos en desuso" (también llamados "stranded assets" en inglés). Debido a esto, el consejo de estabilidad financiera del de las 20 naciones más contaminantes del mundo organizó un equipo colaborativo que se encargará de transmitir la información financiera relacionada con el clima y del mismo modo filtrar la más relevante, para que los inversionistas prevengan los posibles riegos. La incorporación de bonos verdes en la bolsa de valores innovará y encaminará hacia nuevas formas de invertir y patrocinar obligaciones, y este fenómeno se espera que se expanda a nuevos mercados con sostenibilidad ambiental. Del mismo modo, por medio del abordaje de este tema, se quiere resaltar que las 
nuevas finanzas van orientadas a condiciones más seguras y de impacto positivo para la sociedad, que generarán beneficios para todos [22].

La orientación hacia la globalización ha originado nuevos desafíos para el sector privado en aquello relacionado con sus responsabilidades y obligaciones respecto a la sociedad en general. Se considera que la responsabilidad social empresarial obra como un actor estratégico que fomenta la evolución empresarial. El crecimiento de la empresa es una alternativa dependiente de varios aspectos; la responsabilidad social empresarial es uno de ellos, porque protege toda idea originada en la empresa, propiciando el posicionamiento de su marca, transformando la imagen corporativa, recogiendo el favoritismo y la fidelización de la clientela y provocando la perfecta armonía entre la empresa y la comunidad en la que trabaja. En este sentido, surgen análisis como el desarrollado por Andrés Arenas, Eliana Escobar, Juan David Acosta, Lina Monsalve y Diana Oyola [23], quienes indagaron sobre el compromiso que adquieren las empresas colombianas en temas como la Responsabilidad Social Empresarial (RSE) y el desarrollo sostenible, analizándolo desde un punto de vista gerencial, pues es importante ejercer el liderazgo desde una visión filantrópica, en donde se busque como ideal, la colaboración desinteresada de los individuos entre sí, pues el bien común debe primar sobre el bien individual. La RSE es un tema el cual nos toca a todos pero que muy pocos contribuimos a la causa, pues son iniciativas consideradas como una moda, pero en sí, tienen una finalidad clara y es la de mejorar la calidad de vida de los ciudadanos y la protección del medio ambiente.

En Colombia, grandes empresas como Bancolombia, Postobón, Celsia, Alpina, Ecopetrol e Isagen entre otras, son ejemplo de entidades que le han apostado a la propuesta de desarrollo sostenible y responsabilidad social empresarial, mediante la innovación de proyectos que buscan generar impactos positivos desde los diferentes sectores económicos como el turismo, la comercialización, la tecnología, el transporte, el deportivo, el financiero y de servicios, haciendo principal énfasis en el industrial, en donde las malas prácticas empresariales han repercutido negativamente sobre el ambiente y la vida de las personas [23]. La sociedad actual se debate entre el dilema de la producción masiva y la conservación natural, en donde las nuevas empresas tienen una gran responsabilidad y es la de satisfacer las necesidades de consumo, pero de una manera amigable con el planeta; todas estas propuestas van dirigidas a las empresas, pero rara vez se consideran las formas a través de las cuales los ciudadanos contribuyen al desarrollo sostenible mediante una responsabilidad Social individual. Es en este punto en donde se considera que radica el problema, pues muy seguramente las personas no somos conscientes del daño que le ocasionamos al ambiente con simples acciones como las de no reciclar, por eso muchas empresas colombianas están gestionando planes de concientización dentro de las compañías, gestionando no solo inversiones económicas sino también educativas que, desde un enfoque general, son los que más resultados positivos pueden generar. El tema de emisión de bonos verdes y la creación de líneas de créditos verdes, son propuestas que cumplen con una finalidad sostenible, por ello es importante reconocer el papel que cumplen las empresas, pero más aún los ciudadanos, razón por la cual el tema de responsabilidad social debe estar presente en el trabajo, debido a que es una forma de mostrar como una decisión personal puede jugar en pro o en contra del desarrollo sostenible de un país.

La responsabilidad social debe nacer desde el ciudadano del común hasta las entidades públicas, en donde el propósito principal es de concientizarnos sobre lo importante que es priorizar el bien común sobre el bien individual y basados en lo anterior, muchos países se han visto en la necesidad de implementar los impuestos verdes y las regulaciones jurídicas, para que de una u otra forma las personas actúen en pro del medio ambiente. El aspecto normativo es discutido en el informe reportado en la referencia [24], donde expertos en economía ambiental, abordan la problemática de contaminación desde una visión tributaria y legislativa, justificando aquello que dice "el que contamina paga", lo que tiene un propósito no solo económico sino también de concientización. La evolución del hombre ha traído consigo avances en temas de innovación tecnológica, pero a su vez ha repercutido negativamente en los ecosistemas, y ejemplos claros son las catástrofes naturales que han sido provocados por la acción humana, como el desastre de Chernóbil, incendios petroleros de Kuwait, la desaparición casi por completo del mar de Aral, el desastre de Bhopal, el desastre Nuclear de Fukushima, el derrame de golfo de México, entre otros. Lo que ha traído consigo muerte y destrucción, generado fuertes impactos sociales más que económicos, pues hoy por hoy aún se siguen viendo consecuencias como malformaciones congénitas, enfermedades invasivas e improductividad de las zonas geográficas. Todas estas razones suficientes para que la Unión Europea se viera en la necesidad de promulgar reformas tributarias verdes en 1980, básicamente centradas en la creación de impuesto y multas no solo a los entes privados y públicos, sino al ciudadano común que fuera causante de algún tipo de acción que atente contra el bienestar ambiental, como las emisiones de $\mathrm{SO}_{2}$ en la quema de combustibles fósiles, 
fuentes difusas de polución al agua con los fertilizantes y pesticidas, consumo excesivo de agua y energía eléctrica y los medios de transporte los cuales emiten gases que debilitan la capa de ozono. Iniciativas como "el que contamina paga" y la apertura de líneas de crédito verdes para el desarrollo sostenible, impulsan el crecimiento económico de un país, pero de una forma responsable con el planeta.

Otras investigaciones, como la desarrollada por Glorialis González Bermúdez para la Universidad Central "Marta Abreu" de Las Villas (Cuba) [25], se concentran en la Regulación jurídica de los incentivos económico financieros para las Producciones más Limpias; en este trabajo se describe la descomposición el medio ambiente a través del tiempo, por el uso desmedido de productos químicos no degradables y tóxicos en busca de fabricación de productos alimenticios. La autora propone conceder incentivos de distinta índole y valor, que le permita al estado motivar a las personas y organizaciones desde su respectivo rol, encaminándolos al cambio de comportamientos con relación a el efecto que causan al medio ambiente y, por el contrario, adoptar prácticas sanas que lo conserven ya que uno de los mecanismos que utilizan para controlar y concientizar sobre el crecimiento desmedido del deterioro del medio ambiente son los impuestos verdes.

Para finalizar los antecedentes, se mencionará uno que está enfocado a los proyectos sostenibles, de los cuales se ha hablado a lo largo del trabajo, pero no se ha realizado énfasis en ello. En Colombia se han presentado propuestas para estudiar la financiación de proyectos hidroeléctricos a través del mercado de bonos de carbono [26], trabajos en los que se analiza la viabilidad de llevar a cabo la ejecución de proyectos verdes, viendo en los proyectos hidroeléctricos un gran potencial, ya que las zonas geográficas de Colombia, específicamente en el departamento de Antioquia, son zonas muy montañosas, las cuales facilitan la generación de energías renovables, lo que contribuirá no solo con el desarrollo sostenible del país, sino también del planeta, utilizando como medio de financiación los recursos obtenidos a través de la emisión de bonos de carbono o bonos verdes.

Este tema está relacionado directamente con la propuesta de apertura de líneas de productos financieros verdes en la banca colombiana, pues la finalidad de estos es utilizar los recursos recaudados en proyectos amigables con el medio ambiente.

\section{MARCO CONCEPTUAL}

Este trabajo investigativo se encuentra enmarcado por una serie de conceptos claves, que permitirán el desarrollo de una propuesta, cuya finalidad está encaminada al mejoramiento ambiental, siendo los productos financieros verdes un medio para alcanzar el fin. Para cumplir el objetivo general planteado inicialmente, se incursiona en un panorama amplio, en donde se afronta la problemática de la contaminación y el desarrollo sostenible desde diferentes ángulos, buscando alternativas acertadas que permitan contribuir a la mitigación de impactos económicos, sociales y ambientales, generados por la poca responsabilidad social con la que cuentan muchas empresas colombianas. La responsabilidad social empresarial, nace de la concientización que puedan tener las entidades económicas para satisfacer las necesidades del consumo, pero de una manera menos invasiva o perjudicial con el ambiente, lo que da lugar a mencionar otro concepto y es el de la educación ambiental, entendida como "un proceso permanente en el cual los individuos y las comunidades adquieren consciencia de su medio y aprendan los conocimientos, valores, destrezas, las experiencias y también la determinación, que les capacite para actuar individual y colectivamente en la resolución de los problemas ambientales presentes y futuros" [27].

En pocas palabras, lo que se busca con la educación ambiental es hacer conscientes a los sujetos sociales, sobre las causas y consecuencias de una irresponsabilidad ambiental, que sean ellos quienes reconozcan lo que les afecta y cuál es su papel con la sociedad, basados desde los derechos y deberes que se deben cumplir como ciudadanos.

El tema ambiental, además de buscar alcanzar desarrollo sustentable de las comunidades, tiene una finalidad mucho más concreta y es el del bienestar social, en la cual intervienen factores como el acceso a la educación, la salud, la alimentación, la vivienda o los bienes de consumo, entre otras cosas. Para nadie es un secreto, el tema económico es algo que mueve a los países, y no se puede negar que de una u otra forma también contribuyen al bien colectivo, pues en muchos sentidos se mejora la calidad de vida, pero ¿A qué costo se está logrando? Alguna vez nos hemos detenido a pensar ¿De qué sirve tener recursos monetarios, si hay un deterioro progresivo en la salud pública? Todo es un complemento, por eso surge la iniciativa de una propuesta para la apertura de líneas de productos verdes en los bancos colombianos, en donde los beneficios se recibirán de forma recíproca, incentivando al desarrollo económico y social mediante la innovación de proyectos ecológicos, lo que le permitirá a Colombia ser un país altamente competitivo e incursionar en nuevos mercados, el cual será el medio en el que se logre pasar de un nivel subdesarrollo a 
uno desarrollado, en donde las condiciones laborales muy seguramente mejorarán y traerá consigo mayores beneficios a la población.

Todo el planteamiento anterior se ve como algo muy inspirador y filantrópico, es decir, se piensa en el bienestar social y no en el individual, pero esto no se puede quedar en solo palabras, es ahí en donde entra el trabajo en equipo y la colaboración, pensando en que el sector financiero es el sujeto que permitirá llevar a cabo la propuesta.

Los bancos son instituciones que sirven como intermediario financiero, cuyo objetivo principal se basa en la administración de recursos públicos y eso se logra mediante el portafolio de productos que se ofrece, utilizan mecanismos en donde el dinero que captan de sus clientes (personas y empresas) mediante la apertura de cuenta de ahorros o corriente, los CDT'S o las carteras colectivas, lo colocan nuevamente al mercado circulante, mediante la otorgación de créditos, ya sea bajo la modalidad de créditos personales, libranzas, créditos para estudios, tarjetas de crédito entre otras.

Lo que se busca en este trabajo, es que la banca tradicional oriente su portafolio de productos de una manera más ecológica, buscando que la captación de dinero se dé mediante la emisión de bonos verdes y estos recursos sirvan de apoyo para las empresas PYMES colombianas (pequeñas y medianas empresas), las cuales requieren de una capitalización para desarrollar su idea de negocio, con la condición de que los recursos sean utilizados mediante la eco innovación, como su nombre lo indica, es un proceso de innovación mediante el cual se lanzan al mercado productos y servicios que están en pro del cuidado ambiental, lo que les permitirá crecer generando sostenibilidad en el sector económico en que se desenvuelven, y al mismo tiempo mitigar la contaminación ambiental generada por los procesos productivos y las malas prácticas empresariales, los cuales impactan negativamente la salud, el bienestar y la seguridad de los seres vivos que habitan allí. Al final, con la implementación de esta propuesta, se logrará una reducción del consumo desmedido de los recursos naturales, se utilizará la forestación y reforestación como mecanismos encaminados a la producción limpia y no menos importante, está el hecho de que se genera un poco más de conciencia con la situación vivida en muchas comunidades a causa de la mano del hombre, en su búsqueda insaciable de recursos monetarios.

\subsection{MARCo TEÓRICO}

Para empezar con el marco teórico sobre la propuesta de apertura de línea de productos verdes en los bancos colombianos, se toma como referencia el artículo de revista "Inserción del mercado verde en prácticas empresariales colombianas" publicado por Lina María Echeverry, en el cual lo que se hace básicamente es profundizar un poco sobre los mercados verdes y su composición, para ello se empezará dando respuesta al siguiente interrogante:

\subsection{1 ¿Qué es un Mercado verde y cuáles son sus componentes?}

Según organizaciones como la Asociación Americana de Marketing, el término "mercadeo verde" surge en la década de los años 80, y se puede definir como los esfuerzos que hacen los entes empresariales por desarrollar, promover, empacar y recuperar su producción enfocándose en la responsabilidad y sensibilidad ecológica. El mercadeo verde desempeña un papel proactivo, correspondiente con procesos sistemáticos y complejos fundamentados en el diseño de producto y en la propuesta de estrategias de mercadeo que favorezcan la preservación y la protección medio ambiental. Citando a [28], "el mercadeo convencional está en el pasado y el mercadeo verde es el presente y el futuro. Nuevas estrategias e Innovaciones de productos y servicios son las que los consumidores requieren hoy en día. El mercadeo verde o ecológico se está consolidando como una mega tendencia que nace de la sensibilidad que tiene el ser humano frente a su ecosistema y la manera en que las empresas, gobiernos y personas se involucran simultáneamente".

Según [28], el mercadeo verde se compone de tres elementos:

- Establecimiento de estándares novedosos: basado en los objetivos comerciales, transmitiendo que la marca y sus productos son más verdes que las demás alternativas. Se desea evidenciar la diferencia.

- Responsabilidades compartidas: con base en los objetivos comerciales y ambientales a la vez; se quiere transformar la manera en que los productos son usados por las personas, a través de eventos, educación y experiencias de marca. 
- Soporte a la innovación: además de los elementos anteriores se suman los objetivos culturales, los cuales son generadores de nuevos modelos de negocios y nuevas formas de vida.

Cabe resaltar el punto de comparación que se realiza entre el mercadeo convencional y el mercadeo verde, en donde se afirma que las actividades comerciales convencionales hacen parte del pasado, pues el consumidor en general, busca hoy en día, un mercado motivado por ideas innovadoras en los productos y servicios que se ofrece, los temas de calidad y precio es importante, sin dejar de lado la contribución ambiental positiva que se realiza, lo que significa que temas como el de responsabilidad social y educación ambiental, están generando concientización en el consumidor final.

El mercado verde, es el mercado del presente y el mercado del futuro, por lo que Colombia se ha visto en la necesidad de incursionar en los nuevos tipos de negocios ecológicos, para ello han utilizado como estrategia, el apoyo a los microempresarios del sector agropecuario, lo que les permite impulsar proyectos ecológicos rentables. El ministerio de ambiente con ayuda del programa regional de negocios verdes, año tras año realizan una actividad llamada BIOEXPO, la cual tiene por finalidad mostrar el trabajo realizado por centenares de campesinos y pequeños empresarios en temas de eco innovación, de esta forma se busca inversión para generar una inyección de capital y así poder desarrollar la idea de negocio.

Una vez hecha esta salvedad, se profundizará sobre los tipos de negocios verdes planteados inicialmente y los criterios para considerarlo ecológicos, para ello se tomará el Plan Nacional de Negocios Verdes [29] publicado en la página oficial del ministerio de ambiente y desarrollo sostenible colombiano, del cual se extrae el contenido para la siguiente sección.

\subsubsection{Clasificación de los Negocios Verdes}

Parte del siguiente contenido es tomado textualmente del Plan Nacional de Negocios Verdes [29], y se presenta en cursiva.

“Los Negocios Verdes contemplan las actividades económicas en las que se ofertan bienes o servicios, que incorporan buenas prácticas ambientales, sociales y económicas con enfoque de ciclo de vida, contribuyendo a la conservación del ambiente como capital natural que soporta el desarrollo del territorio.

La clasificación de los negocios verdes parte de tres grandes categorías:

\section{a. Bienes y servicios sostenibles provenientes de los recursos naturales}

- Agro sistemas sostenibles: Unidad de producción de alimentos, materias primas, servicios ambientales y otros satisfactores de origen agrícola basados en el manejo agroecológico tendiente al mejoramiento social, económico y ambiental a corto, mediano y largo plazo para beneficio de la sociedad, sin deteriorar la base de los recursos naturales

- Bio comercio: se refiere al conjunto de actividades de recolección y/o producción, procesamiento y comercialización de bienes y servicios derivados de la biodiversidad nativa, bajo criterios de sostenibilidad ambiental, social y económica.

- Negocios para la restauración: proceso de asistir al restablecimiento de un ecosistema que ha sido degradado, dañado o destruido. Entendiendo que un ecosistema ha sido recuperado cuando contiene todos los elementos bióticos y abióticos que le permiten continuar por sí mismo con su desarrollo.

\section{b. Eco productos industriales}

- Aprovechamiento y valoración de residuos: El aprovechamiento de los residuos sólidos para los diferentes usos, se da de la mejor forma si estos han sido separados. La separación de los residuos se puede lograr de varias formas que tienen diferentes grados de complejidad y de cooperación ciudadana. Por ejemplo, la separación se puede hacer en el sitio de generación de los residuos, bien sea en los hogares o en las instituciones, lo que se denomina separación en la fuente, en cuyo caso se requiere un alto grado de cooperación y una baja complejidad en la tecnología de separación y que sería de una enorme ayuda para los procesos; o la separación se puede hacer a partir de la basura mezclada, en estaciones especializadas para tal fin, que usualmente retardan demasiado el trabajo y a veces no se obtiene la mayor satisfacción. 
- Fuentes no convencionales de energía renovable: Son todas aquellas fuentes de generación energéticas en las cuales no se incurre en el consumo gasto o agotamiento de su fuente generadora. Entre estas fuentes de energías podemos mencionar a la energía hidráulica proveniente de la fuerza motriz del agua. La energía solar, capturada del sol mediante la radiación solar. La energía eólica, nutrida por la fuerza mecánica del viento, y la fuente mareomotriz, que se alimenta de la fuerza generadora del oleaje de los océanos.

- Construcción sostenible: constituye una manera de satisfacer las necesidades de vivienda e infraestructura del presente sin comprometer la capacidad de generaciones futuras para satisfacer sus propias necesidades en tiempos venideros. La Construcción Sostenible se puede definir como aquella que, teniendo especial respeto y compromiso con el medio ambiente, implica el uso eficiente de la energía y del agua, los recursos y materiales no perjudiciales para el medio ambiente, resulta más saludable y se dirige hacia una reducción de los impactos ambientales

\section{c. Mercados de carbono.}

- El regulado: Es utilizado por empresas y gobiernos que, por ley, tienen que rendir cuentas de sus emisiones de GEl. Está regulado por regímenes obligatorios de reducción de carbono, ya sean nacionales, regionales o internacionales. Los tres mecanismos del Protocolo de Kioto son muy importantes para el mercado regulado: el Mecanismo para un Desarrollo Limpio (MDL), la Ejecución Conjunta (Jl, siglas en inglés) y el Régimen para el comercio de derechos de emisión de GEI de la Unión Europea (ETS, siglas en inglés). Algunos países no han aceptado legalmente el Protocolo de Kioto, pero tienen otros esquemas de reducción de GEI vinculantes legalmente, a nivel estatal o regional.

- El voluntario: Como reflejo de los mecanismos flexibles del Protocolo de Kioto, surgen los Mercados Voluntarios de Carbono (MVC) creados por ciudadanos particulares y organizaciones públicas y privadas que toman conciencia de su responsabilidad en el cambio climático y voluntariamente desean participar activamente. El mercado voluntario facilita a las entidades y a las personas que no están dentro de los sectores regulados asumir su compromiso con el cuidado del clima "compensando" sus emisiones en proyectos limpios en países en desarrollo.

Aunque los mecanismos voluntarios no están regulados $y$, consecuentemente, generan controversias, se han revelado como innovadores, ágiles y flexibles.

A partir de las clases de negocios ecológicos, surge una iniciativa por parte del plan de Negocios verdes, la cual va orientada a la definición de doce criterios que permiten evaluar de manera diagnóstica, los aspectos fundamentales en el contexto de sostenibilidad utilizado por empresas con negocios verdes, el objetivo es evaluar cómo la oferta de bienes y servicios bajo esta modalidad, cumplen con los estándares de calidad y a su vez generan impactos ambientales positivos, mediante la productividad responsable, la protección y el consumo eficiente de recursos renovables y no renovables.

\subsection{Criterios de identificación de Negocios Verdes.}

Los criterios de Negocios Verdes son importantes para asegurar los beneficios directos derivados "al productor, consumidor y a la sociedad; permitir apreciar relaciones vitales del bien o servicio con aspectos como la biodiversidad, productividad, protección de los recursos renovables y no renovables; e informar al consumidor y brindarle herramientas que puedan ejercer su derecho a un consumo responsable, con pleno conocimiento del impacto de sus objetos de compra (ONVS, 2014)" como se cita en [30].

Adicionalmente, "el objeto fundamental de los criterios de Negocios Verdes es verificar que los bienes $y$ servicios se enmarcan en la definición y características de los negocios verdes y si no están cumpliéndolos a cabalidad, adelantar una ruta a través del plan de mejora y buscar su implementación con el apoyo de instituciones a nivel nacional y regional que puedan aportar al proceso." [30]

La Figura 1 presenta una ilustración en donde se observan los 12 criterios que debe cumplir una iniciativa de negocio para considerarse como verde, partiendo de un estudio exhaustivo de la propuesta desde el planteamiento de la idea de emprendimiento hasta el producto o servicio que obtiene el consumidor final, en 
donde cada uno de los procesos intermedios debe estar dirigido o pensado a la protección y conservación de los recursos. Uno de los principales enfoques que tiene este criterio, es el de desarrollar e infundir en las nuevas empresas colombianas, una responsabilidad social empresarial a nivel interno y externo de la compañía.

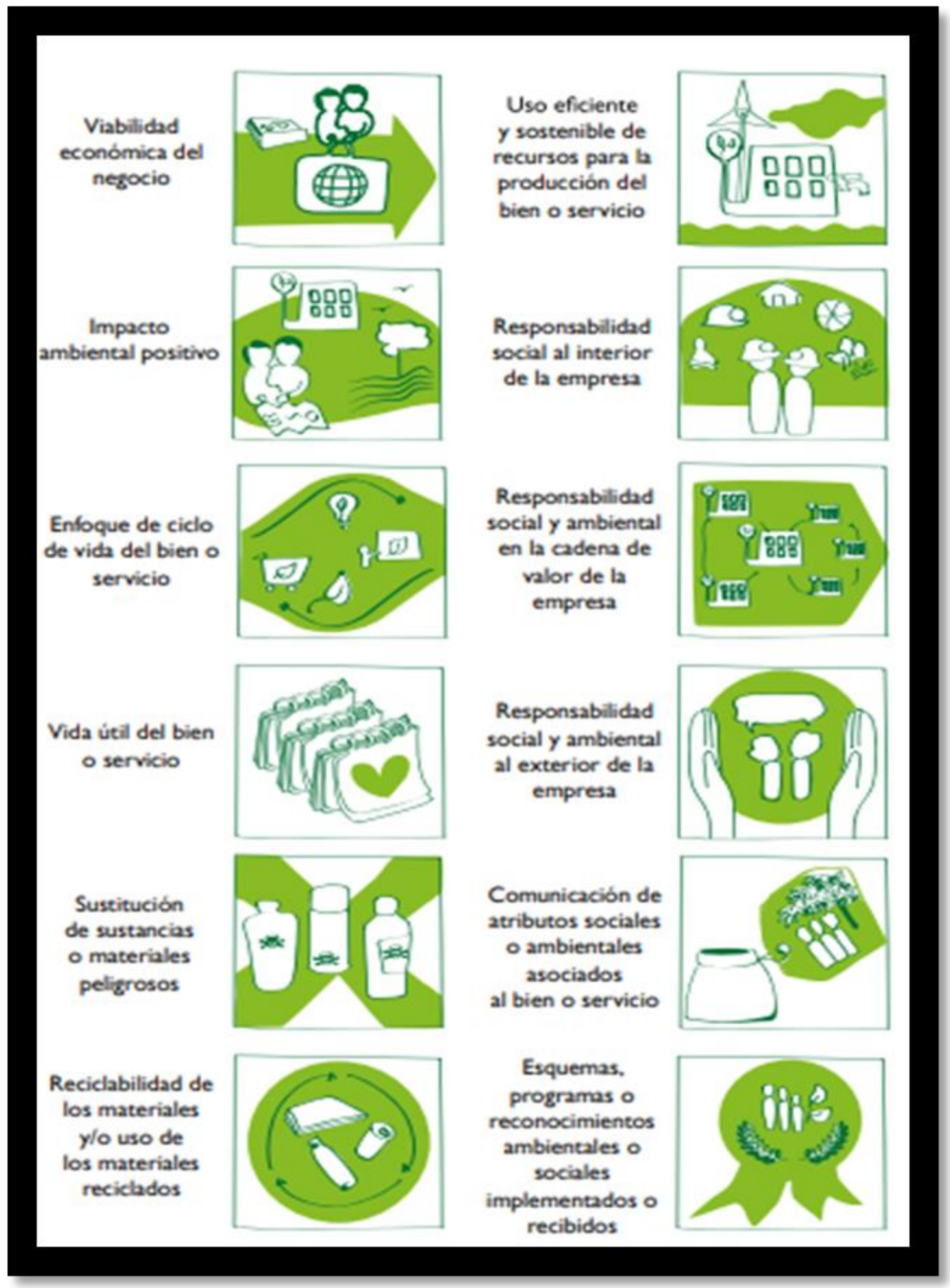

Figura 1. Doce criterios generales de Negocios Verdes según el ministerio de ambiente de Colombia [30] 
Daniela Rua Usme, Adriana María Ospina, Catalina Ramírez López, Paola Ortiz \& Julián Alberto Patiño-Murillo

Ahora bien, después de contextualizar sobre los mercados verdes presentes en Colombia, es importante conocer ejemplos de compañías que han dirigido sus ideas de negocio, bajo los parámetros para obtener una economía sustentable, para ello se tomará un artículo publicado en la revista CECODES en el año 2016, en donde hablan de las EMPRESAS MAS SOSTENIBLES DE COLOMBIA [31], que expone que "Grupo Nutresa, SURA, Argos, ISA y Cementos Argos han sido incluidas en el índice de Sostenibilidad Dow Jones, indicador que evalúa el desempeño económico, ambiental y social de las compañías presentes en la bolsa.

Algunos fragmentos textuales del artículo indican lo siguiente (en cursiva, tomado de [31]):

“Grupo Nutresa: Dentro del listado global, Grupo Nutresa es la única compañía del sector de alimentos (en países emergentes) que ha sido incluida en el índice de Sostenibilidad Dow Jones.

Desde el 2014 la organización definió seis prioridades para su estrategia de sostenibilidad, las cuales se enfocan en implementar políticas de ética y responsabilidad dentro del gobierno corporativo, generar una cultura de innovación, garantizar un empleo decente, tener un abastecimiento sostenible, usar racionalmente de los recursos naturales y fomentar una vida saludable.

Este año, Grupo Nutresa alcanzó el máximo puntaje en gestión de conducta riesgos y crisis. Así mismo, obtuvo la mayor calificación en reporte social e indicadores de prácticas laborales y derechos humanos. En materia ambiental alcanzó la máxima calificación en reporte ambiental, abastecimiento en materias primas, entre otros.

Grupo SURA: Es la única compañía latinoamericana perteneciente al sector de Servicios Financieros Diversos, que ha sido incluida en este índice. La empresa ha ingresado a esta lista debido a que fortaleció su política anticrimen, realizó una buena gestión de riesgos asociada al cambio climático y al área de la seguridad en el trabajo.

Cabe recordar que recientemente SURA presentó un seguro para generar confianza y seguridad de los potenciales inversionistas de programas de eficiencia energética, lo que demuestra el compromiso de esta organización por promover proyectos que favorezcan al medio ambiente.

La inclusión de Grupo Sura al Índice de Sostenibilidad Dow Jones, le permitió identificar a la organización los aspectos que debe seguir fortaleciendo en su gestión.

Grupo Argos: Cuenta con un modelo de Sostenibilidad que le ha permitido crecer de manera sostenible, garantizando la conservación de recursos naturales y fomentando el desarrollo integral de las comunidades que logra impactar.

Actualmente, Grupo Argos apoya el proyecto Mujeres Digitales con el que capacitan a las mujeres en temas de liderazgo, creatividad y conocimiento de sus derechos. Así mismo promueve la investigación de la riqueza botánica del país y apoyan a fundaciones como: La Cueva, Jardín Botánico de Medellín, Fundación Integrar, Taller de Letras, Parque Cultural del Caribe, Fútbol con Corazón, entre otras, con las que logran contribuir al desarrollo social del país.

ISA: La compañía obtuvo una calificación de 100 puntos en las categorías de biodiversidad, transmisión y una de las mejores calificaciones en seguridad de la información y ciber seguridad. De igual forma, se destaca por tener un buen relacionamiento con sus grupos de interés, por hacer una buena gestión social y un buen manejo de crisis. La compañía ha incorporado la Sostenibilidad a su enfoque de negocios. Esto les permite actuar de manera responsable, transparente y gestionar las oportunidades, impactos y riesgos económicos.

Cementos Argos: La compañía obtuvo el reconocimiento de ser una de las cementeras más sostenibles del mundo tras lograr el mejor puntaje de su sector en el Índice de Sostenibilidad Dow Jones. Esto lo logró por su alto desempeño en Biodiversidad, Ecoeficiencia, Agua, Reporte Social, Prácticas laborales, Derechos Humanos, entre otros. Esto se debe a que la política de sostenibilidad de Cementos Argos se basa en siete promesas de valor, las cuales comprenden a sus colaboradores, comunidades, clientes, proveedores, comunidades, accionistas, medio ambiente y autoridades, con esto garantizan la implementación de prácticas sostenibles que mitiguen su impacto ambiental.

De hecho, Cementos Argos en alianza con la Alcaldía de Bogotá han creado una solución para el problema ambiental que generan las llantas usadas en la capital colombiana. Esto lo logran a través de su técnica de procesamiento de Argos." [31]

El ingreso de estas compañías al Índice de Sostenibilidad de Dow Jones demuestra cuán comprometidas están las organizaciones colombianas para contribuir al desarrollo social, económico y ambiental. Lo que reitera una vez más, el potencial que tiene el país para llevar a cabo proyectos financieros pensados desde los términos ecológicos. 
La propuesta de apertura de una línea de productos financieros verdes en los bancos colombianos nace como una idea en la que se unen los instrumentos financieros utilizados por la banca convencional (captación y colocación), pero desde un pensamiento basado en lo social más que en lo lucrativo.

Muchas corporaciones financieras del país han empezado a implementar productos verdes en el portafolio ofrecido al pueblo colombiano, pero la idea es incursionar si no es todo, por lo menos en la gran mayoría de corporaciones que se encuentran en el sector financiero actualmente, haciéndoles la invitación para que se unan al mercado verde, ya que el mercado convencional está quedando atrás, por el sinnúmero de propuestas innovadoras que se presentan continuamente.

La idea es cambiar ese Chip, en el que lo lucrativo es el único importante y empezar a trabajar de una forma en la que se obtengan recursos monetarios, sin necesidad de pasar por encima del bien social.

Una alternativa puede ser el utilizar como sistema de captación de recursos, la emisión de bonos de carbono voluntarios, es decir, son bonos que no tienen regulaciones rigurosas, ya que las personas o compañías que los obtienen no son necesariamente corporaciones que perturban el bienestar ambiental, todo lo contrario, son inversionistas en donde el tema de concientización está presente y ven esta, como una buena alternativa de crear valor sostenible. Varios estudios hacen un comparativo sobre las tasas de interés que se recibe a cambio de un bono común y un bono verde, estos últimos son un poco más rentables, lo que los convierte en una opción atractiva a la hora de invertir.

Esa sería la idea para recaudar fondos, ahora bien, ¿En que consta la parte de colocación? Desde una perspectiva amplia, este segundo paso es muchos más sencillo o viable que el planteado inicialmente, la idea es que los bancos abran líneas de crédito con enfoque ecológico, es decir, poner en circulación el dinero recaudado en proyectos sustentables, en los cuales las micro y pequeñas empresas serán las más beneficiadas, siempre y cuando sus ideas de negocio estén encaminadas a la protección o recuperación del ambiente.

En ese orden de ideas, se profundizará sobre el mecanismo financiero utilizado por los bancos para recaudar fondos, que en la propuesta planteada se basa en la emisión de bonos verdes voluntarios, en donde se hablará de sus inicios, el factor diferencial a un bono tradicional, a quienes va dirigida esta propuesta de inversión, en qué se beneficia al país, entre otros temas. El tema de los bonos verdes será discutido en la próxima sección, no sin antes reconocer que "en un entorno en el que las empresas tienen cada vez más conciencia sobre la importancia de la sostenibilidad, los bonos verdes se han consolidado como una alternativa de financiación. En 2016 se superaron los 87.000 millones de dólares en emisiones en todo el mundo, cifra que duplicaba los 42.000 millones de 2015" [32].

\section{3 ¿QUÉ ES UN BONO VERDE Y EN QUÉ SE DIFERENCIA DE UN BONO COMÚN?}

Para responder se remitirá a la información suministrada por Bancolombia, en donde se plantea lo siguiente: "Los bonos verdes son un tipo de inversión de renta fija, los cuales cuentan con vencimiento y calificación de riesgo, donde los recursos se destinan exclusivamente en proyectos sostenibles. El destino de ese capital es lo que realmente diferencia a los bonos verdes de los bonos comunes, porque los recursos deben ser usados en la financiación de proyectos que ayuden a combatir el cambio climático a partir de las energías y construcciones sostenibles, producción más limpia, entre otros." [33].

Retomando la clasificación de Negocios Verdes planteada inicialmente, es importante aclarar que el mercado de los bonos de carbono se encuentra dentro de esta clasificación y a su vez se subdividen en bonos regulados y bonos voluntarios, para ello se utilizará como fuente de profundización, un artículo publicado en la revista Ecodes del año 2017, en el que se cita lo siguiente:

"Los bonos verdes regulados son utilizados por empresas y gobiernos que, por ley, tienen que rendir cuentas de sus emisiones de GEl. Está regulado por regímenes obligatorios de reducción de carbono, ya sean nacionales, regionales o internacionales. Frente a las obligaciones y críticas generadas por los mercados de conformidad, y como reflejo de los mecanismos flexibles del Protocolo de Kioto, surgen los Mercados Voluntarios de Carbono (MVC) creados por ciudadanos particulares y organizaciones públicas y privadas que toman conciencia de su responsabilidad en el cambio climático y voluntariamente desean participar activamente.

El mercado

voluntario facilita a las entidades y a las personas que no están dentro de los sectores regulados asumir su compromiso con el cuidado del clima "compensando" sus emisiones en proyectos limpios en países en desarrollo.

Aunque los mecanismos voluntarios no están regulados y, consecuentemente, generan controversias, se han revelado como innovadores, ágiles y flexibles. Estos mercados, a menudo difíciles de entender, representan 
la repuesta de compañías y los ciudadanos al cambio climático y tienen el potencial de ser una herramienta inmediata para la acción mientras la comunidad internacional se queda atascada a la hora de implementar un marco para el cambio climático eficiente" [34]

De acuerdo con la misma fuente [34], los mercados voluntarios se subdividen en:

- Over the counter market (OTC), donde se produce el intercambio de reducciones de carbono generadas solamente mediante proyectos de compensación, y que también se conoce como Mercado Voluntario puro.

- Chicago Climate Change (CCX), donde se produce el intercambio tanto de reducciones de carbono como de derechos de emisión que se generan mediante proyectos de compensación.

\section{4 ¿CUÁLES SON LOS BENEFICIOS Y DESVENTAJAS DE EMITIR BONOS ECOLÓGICOS?}

De acuerdo con [33], para el inversionista y el emisor de bonos de carbono existen importantes beneficios pero siempre el impacto ambiental y social debe prevalecer por sobre los beneficios individuales. Algunas de las ventajas a resaltar son:

- La diversificación de inversionistas.

- El diálogo más estrecho con los inversionistas.

- La creación de un mercado que permita la financiación de proyectos sostenibles.

Usualmente, el inversionista que desee financiar proyectos sostenibles encontrará que propuestas de inversión en las siguientes industrias:

- Transporte público.

- Energía.

- Construcción e industria.

- Administración del agua.

- Desechos y control de la polución.

- Agricultura y forestación

Algunas de las principales desventajas de la emisión de bonos verdes son:

- "La emisión requiere el cumplimiento de ciertos requisitos adicionales a los de emisión de un bono tradicional, que pueden generar costos y procedimientos adicionales.

- El uso de los fondos debe monitorearse, incluida la presentación de informes periódicos." [33].

\subsection{1 ¿Quién puede emitir estos bonos?}

De acuerdo con [35], los bonos de carbono pueden ser emitidos por "cualquier entidad con calificación crediticia (banca de desarrollo, comercial, corporativos, gobiernos nacionales y locales). Las carteras de crédito también pueden ser usadas como activos verdes, es decir se pueden comerciar en el mercado secundario".

Con la emisión de bonos verdes se posibilita el desarrollo de proyectos para cuidar el entorno ambiental, ya que constituyen "un instrumento de renta fija mediante el cual los gobiernos y las empresas obtienen recursos para financiar únicamente proyectos ambientales" [33].

Los bonos verdes pueden ser comprados por diferentes tipos de inversionistas, tales como [33].:

"Inversionistas verdes: invierten en proyectos que protegen los recursos ambientales y que mitigan los efectos del cambio climático.

Inversionistas socialmente responsables: incorporan criterios éticos, sociales y ambientales en el momento de tomar decisiones de inversión.

Gestores de activos: Encargados de la gestión responsable del capital, quienes identifican impactos positivos en el rendimiento de las inversiones verdes.

Bonos/Corporaciones/Aseguradoras: Bancos y corporaciones cuyas tesorerías avanzan hacia la inversión responsable" [33]. 
Los bonos verdes son atractivos para aquellas empresas que tengan en mente iniciar con un proyecto verde, porque ofrece la posibilidad de tener acceso a recursos rápidamente (en la medida que se cumpla con las características de un proyecto verde) y sin requerir de una gran cantidad de activos para como respaldo de la inversión. [35]

Una vez expuesto el tema de los bonos de carbono desde los diferentes ámbitos que se consideran esenciales para contextualizar, es relevante mencionar el alineamiento que debe tener con los Green Bond Principles (GBP), cuya finalidad es la promoción de la integridad del mercado de bonos verdes mediante directrices que recomiendan transparencia, publicidad y reporte de informes.

\subsection{Lineamientos establecidos en los PRINCIPIOS de BonOS Verdes O GREeN BOND PRINCIPLES}

Los Green Bonds Principles (GBP) sugieren un proceso claro de información de manera que todos los interesados en la temática puedan entender las características de un Bono Verde, enfatizando la obligación de mantener la transparencia, precisión e integridad de la información relacionada con la sostenibilidad ambiental que va a ser publicada y reportada para la toma de decisiones estratégicas de quienes inviertan. Los GBP poseen cuatro elementos, tal como se enuncia en [33] (tomado directamente, en cursiva):

- Uso de las ganancias en:

- Energía renovable

- Eficiencia energética (incluyendo edificios eficientes)

- Gestión sostenible de los residuos

- Uso sostenible de la tierra (incluyendo silvicultura y agricultura sostenible)

- Conservación de la biodiversidad

- Medios de transporte limpios

- Gestión sostenible del agua (incluyendo agua limpia y/o potable)

- Adaptación al cambio climático

- Proceso para la evaluación y selección de los proyectos

- Un proceso para determinar cómo los proyectos se ajustan a las categorías elegibles de Proyectos Verdes

- Los criterios que hacen que los proyectos sean elegibles para el uso de las ganancias de los Bonos Verdes

- Los objetivos de cada proyecto

\section{- Gestión de las ganancias}

Formas apropiadas de trazabilidad por parte del emisor además de contar con un proceso interno formal relacionado con los préstamos y las operaciones de inversión para Proyectos Verdes realizados por el emisor.

- Reporte

Además de reportar sobre el uso de las ganancias y la inversión temporal de ganancias no utilizadas, los emisores deben proporcionar al menos una vez al año una lista de proyectos para los que las ganancias de los Bonos han sido invertidas. [33].

\subsubsection{Certificación, clasificación y objetivos de Bonos ecológicos}

Para calificar los bonos como verdes, el producto debe estar adecuadamente identificado, y determinar el impacto medioambiental real, explicando el procedimiento para gestionar los recursos con asistencia de un auditor y realizar informes periódicos sobre la utilización de los fondos. Como se señala en algunos artículos, "el objetivo de los bonos verdes es convertir la herramienta de deuda en un movilizador de recursos enfocados 
a proyectos verdes o "amigables con el medio ambiente". Los bonos verdes son una fórmula innovadora que les da a los inversionistas la oportunidad de invertir en proyectos con bajas emisiones de carbono, eficientes energéticamente y con el tratamiento de agua adecuado, lo cual ayuda a cuidar los recursos escasos. Sumado a lo anterior los bonos verdes son muy atractivos como inversión puesto que gran parte de estos tienen calificación "AAA" muy poco riesgo y paga entre 1.5 a 3 puntos por encima de indicadores como inflación (depende del bono)".[35]

Según un estudio realizado por la agencia de calificación de riesgos "Moody's", se evidencia el crecimiento exponencial que ha surgido en el transcurso de esta última década en lo relativo a la emisión de bonos verdes, por otro lado, se muestra cómo ha sido la participación de los diferentes sectores económicos para la colocación de recursos monetarios, para ello se utilizará la gráfica comparativa de la figura 2.

\section{EL NEGOCIO SOSTENIBLE}

\section{EMISIONES DE BONOS VERDES}

\section{En miles de millones de dólares}

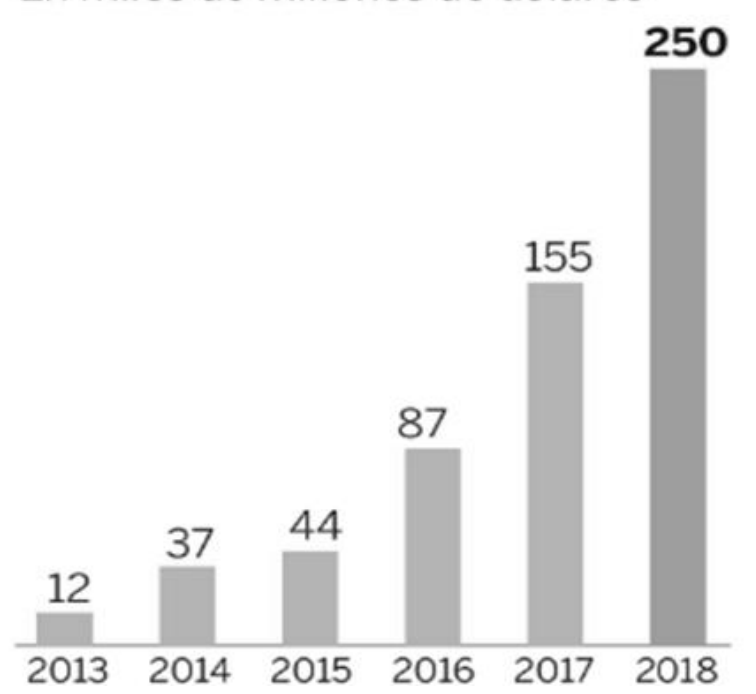

\section{QUIÉN COLOCA ESTOS TÍTULOS}

En \%

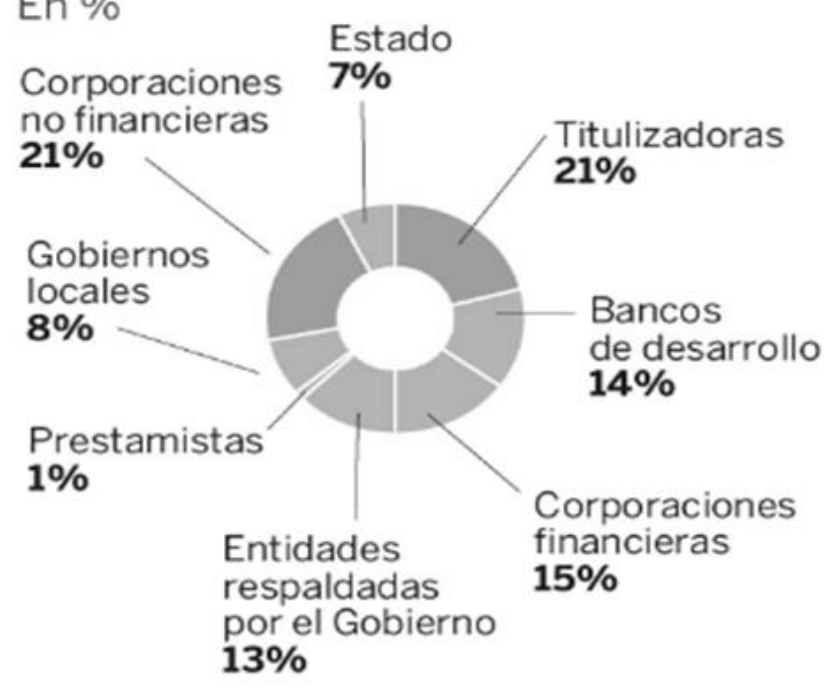

Figura 2. Crecimiento y colocación en el mercado de los bonos verdes (Adaptado de [36]).

Esta tendencia de crecimiento se ha mantenido y se espera que aumente: "Ya sea por moda, por concienciación medioambiental o por simple lavado de cara de la reputación, el mercado de bonos verdes crece de forma exponencial. En 2017 diferentes empresas privadas y organismos públicos emitieron este tipo de deuda por valor de 155.000 millones de euros, un 78\% más que el año anterior. Moody's cree que esta tendencia se acelerará y prevé que el volumen de colocaciones en 2018 alcance los 250.000 millones.'[36].

Ahora bien, después de haber hablado de los bonos de carbono como mecanismo para recaudar recursos monetarios, se entrará en materia en el segundo punto de la discusión, sobre la apertura de línea de productos financieros verdes en las corporaciones bancarias colombianas, en donde los créditos para la destinación ecológica es el punto central a tratar y más aun sabiendo que Colombia es uno de los países participes en el acuerdo de Paris, donde lo que se busca incentivar es la reducción de gases de efecto invernadero.

Se hará énfasis en información proveniente de Asobancaria, que es un conglomerado de instituciones financieras nacionales y extranjeras, la cual centraliza la información económica del sector bancario y promulga temas de interés financiero como estudios de mercado y datos estadísticos, razón suficiente para tenerla como referente en el trabajo investigativo planteado. 


\section{6 ¿QUÉ ES UN CRÉDITO VERDE?}

En esta sección se hace uso de información de Asobancaria [37] (tomada directamente, en cursiva), y donde se establece que:

"Del compromiso que han venido adquiriendo las entidades bancarias con la sostenibilidad, nacen las líneas de financiamiento verde, es decir, créditos orientados al financiamiento de proyectos que promuevan el uso sostenible de los recursos naturales renovables, la protección del medio ambiente y la competitividad de los sectores productivos del país, contribuyendo al mejoramiento de la calidad de vida de la población e impactando positivamente el medio ambiente. Las líneas de financiamiento verde buscan incentivar la creación y desarrollo de proyectos que promuevan la protección y conservación del medio ambiente, además de la adopción de procesos de producción sostenible. Dichos proyectos deben contar con la revisión y verificación del beneficio ambiental que se va a financiar y/o la mitigación de daños en el mismo, pues lo realmente importante es la obtención de resultados junto al desarrollo exitoso y sostenible de los proyectos.

Para aplicar a una línea de financiamiento verde, el proyecto debe estar relacionado con la prevención, manejo o mitigación de los efectos ambientales adversos, y apuntar hacia la adaptación al cambio climático. Algunas de las áreas relacionadas podrían ser [37]:

- Eficiencia energética

- Generar o aumentar el uso de energías renovables

- Infraestructura sostenible

- Ecoturismo

De acuerdo con Asobancaria [37] (tomada directamente, en cursiva), los siguientes son algunos de los beneficios generales de adquirir crédito ambiental:

- Incentivos como el reembolso de una parte de la inversión, dependiendo de reducción del impacto ambiental

- Algunas entidades financieras cuentan con tasas preferenciales

- Incentivos tributarios

- Actualización tecnológica

- Reducción de impactos ambientales

- Aumento en la productividad de la empresa y mejoramiento del entorno de trabajo

Además, según la información de Asobancaria [37], "el proceso para acceder el crédito verde varía de acuerdo con la entidad financiera que se elija para solicitar financiación, aun así, existen ciertos requisitos generales que las empresas deben cumplir para poder aplicar. Las entidades financieras que ofrecen este tipo de líneas acceden a estas a través de tres mecanismos:

1. Líneas Propias, es decir cada banco comercial puede estructurar sus líneas de acuerdo con sus proyecciones.

2. Bancas multilaterales, son líneas que se ofrecen a través del Banco Interamericano de DesarrolloBID, Banco Mundial, la Corporación Andina de Fomento, entre otros para ser colocadas por medio de la banca comercial

3. Líneas de redescuento: son las líneas que se obtienen de los bancos de segundo piso como Bancoldex, Findeter, Finagro" [37]

Citando nuevamente a Asobancaria [37] (tomada directamente, en cursiva), estas son las características de un crédito verde en Colombia:

- Financiación de uno a cinco años para tasas variables.

- La periodicidad de pago de interés es:

- DTF: mensual, trimestral, semestral o anual.

- IBR: se fija de acuerdo con el crédito y, la periodicidad de pago de intereses es

- IBR Mensual: pago de intereses únicamente mensuales.

- IBR Trimestral: pago de intereses trimestrales. 
- El pago de capital puede ser mensual, trimestral, semestral, anual o con plan de pagos si el pago no es regular.

- Desembolso mediante abono a cuenta de ahorros o corriente, expedición de cheque o a la cuenta de un tercero.

- Para personas naturales el crédito incluye Seguro de Vida.

Actualmente en Colombia, existen bancos que incursionan en el tema de financiamiento verde, en donde instituciones financieras como Bancolombia, Davivienda, Bancoldex y Línea de crédito ambiental (seco), son los cuatro principales en abordar este tema, cada uno lo hace desde sus propias las metodologías utilizadas para desarrollar su labor de financiamiento, por lo cual se considera importante analizar la propuesta de crédito verde ofrecida por cada entidad y así poder identificar cual se tomaría como un ejemplo idóneo, para que los bancos colombianos empiecen a crear valor a partir de la sostenibilidad ambiental.

La figura 3 presenta un comparativo de las líneas de crédito verde en Colombia. Analizando dicha ilustración, se observa como cada entidad bancaria, dentro de sus propuestas planteadas para el financiamiento verde tienen factores diferenciadores, cada uno enfocado desde sus políticas de crédito establecidas. A nivel comparativo todas tienen su pro y su contra, lo cual se compensa entre sí, ya sea los plazos pactados para pagos, el periodo de gracia otorgado, las tasas de interés para el financiamiento o el enfoque que le dan a los recursos prestados. Cabe resaltar, la labor tan importante que están realizando estas instituciones del sector bancario, para contribuir al desarrollo sostenible del país, sin embargo, se considera que la metodología utilizada por la corporación financiera SECO es la más idónea, ya que plantean como medio motivacional, la propuesta de reembolso del $25 \%$ del total del crédito, si se logra evidenciar resultados de alto impacto positivo, en el tema de disminución de agentes contaminantes. Observando esto, el tema de conservación y protección ecológica, no se debe convertir en una excusa para no ponerla en marcha, debido a que todos tenemos el mismo nivel de alcance para contribuir.

\section{BONOS VERDES EMITIDOS POR EL GOBIERNO COLOMBIANO}

Al emitir los Bonos Verdes, Bancóldex ha consolidado su enfoque estratégico para impulsar el crecimiento empresarial y aumentar la productividad y competitividad del sector empresarial colombiano, buscando promover el adecuado uso de los recursos naturales y el bienestar de la sociedad en las actividades presentes y futuras. Para cumplir este objetivo, Bancóldex ha participado en acciones para fortalecer el compromiso del sector financiero con el desarrollo sostenible. Mediante su adhesión al Protocolo Verde [38], ha movilizado recursos para mitigar el impacto de la actividad productiva, y ha desempeñado un papel pionero en la incorporación de criterios ambientales en los procesos de concesión de créditos.

Al emitir sus primeros Bonos Verdes, Bancóldex buscó involucrar al sector privado en la financiación de proyectos productivos que contribuyan a la protección del medio ambiente, el uso eficiente de los recursos y la mitigación y adaptación al cambio climático, con un impacto tangible y medible. El seguimiento y los resultados alcanzados están en línea con los principios internacionales de la directriz de proceso voluntario para la emisión Bonos Verdes, establecidos por la Asociación Internacional del Mercado de Capitales (ICMA, International Capital Market Association) [39]. Los proyectos, que se financian o refinancian utilizando recursos de la emisión de los Bonos Verdes, son desarrollados por empresas en Colombia que tienen como objetivo generar beneficios ambientales.

Estas actividades buscan:

- Optimizar el uso de los recursos.

- Utilizar y gestionar correctamente los residuos generados en el proceso de producción.

- Uso de la energía de una manera cada vez más eficiente.

- Incorporar prácticas sostenibles, incluida la sustitución de tecnología ineficiente o basada en combustibles fósiles por tecnología limpia.

- Controlar la contaminación. 


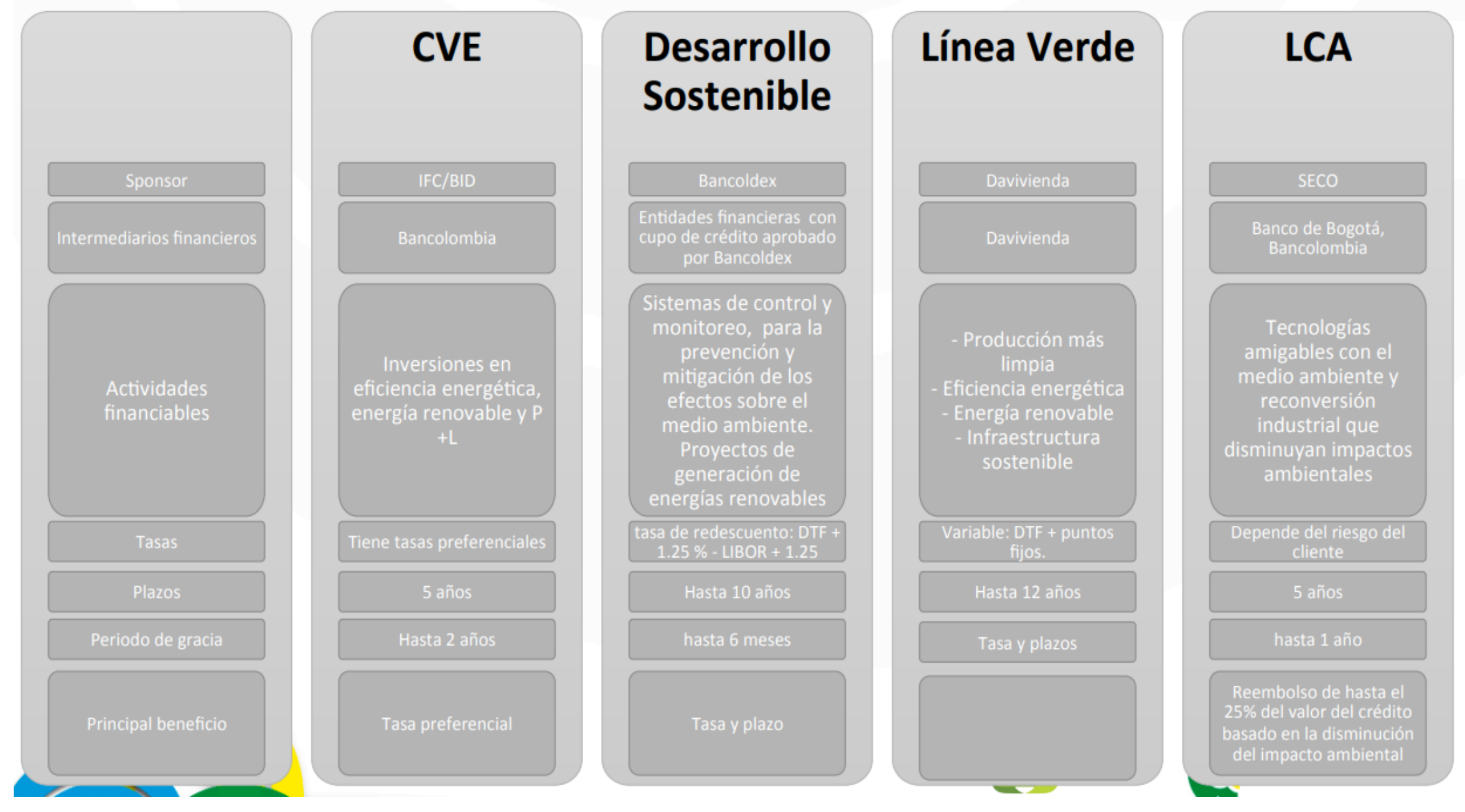

Figura 3. Líneas de Crédito Verde en Colombia, corporaciones financieras colombianas y productos verdes [35] 


\subsection{PROCESO DE EVALUACIÓN Y SELECCION DE PROYECTOS}

Los recursos de Bonos Verdes respaldan las iniciativas de las empresas colombianas para usar y reducir eficientemente la contaminación de recursos como el aire, el agua y la tierra, invertir en eficiencia energética e incorporar energía renovable en todos los sectores de la economía. Estos esfuerzos están en línea con las contribuciones previstas determinadas a nivel nacional (INDC) anunciadas en el Acuerdo de París y la estrategia de sostenibilidad de Bancóldex. Los proyectos empresariales elegidos para el uso de los recursos cumplieron uno o más de los cinco criterios de elegibilidad para el financiamiento a través de las líneas de crédito verdes que están directamente vinculadas con el objetivo de los Bonos Verdes de Bancóldex:

- Desarrollo Sostenible

- Eficiencia Energética y Energía Renovable

- Modernización de Negocios

Los recursos de los Bonos Verdes se destinaron en su totalidad a financiar las actividades comerciales seleccionadas según los criterios mencionados anteriormente, de conformidad con las disposiciones del Marco [39].

De acuerdo con el principio de transparencia, Bancóldex presentó la información consolidada sobre el uso de los recursos de sus Bonos Verdes en términos del número de beneficiarios, la distribución por categoría de la cartera total, el valor promedio de los desembolsos y la distribución regional. También presenta el impacto ambiental positivo de cuatro proyectos representativos que, en resumen, ejemplifican los logros esperados y contribuyen significativamente a los objetivos de los Bonos Verdes [40].

Considerando los criterios de elegibilidad y exclusión, Bancóldex identificó en 2017 una cartera que incluía 117 proyectos que podrían recibir asignaciones de su emisión de bonos verdes. Esta cartera ascendía a aproximadamente USD 50,0 millones (COP 145.439 millones) millones al 26 de mayo de 2017, lo que representa el $79 \%$ del uso de los ingresos del bono verde en el momento de la emisión. A continuación, se presenta una distribución de la cartera de proyectos por criterios de elegibilidad [40].

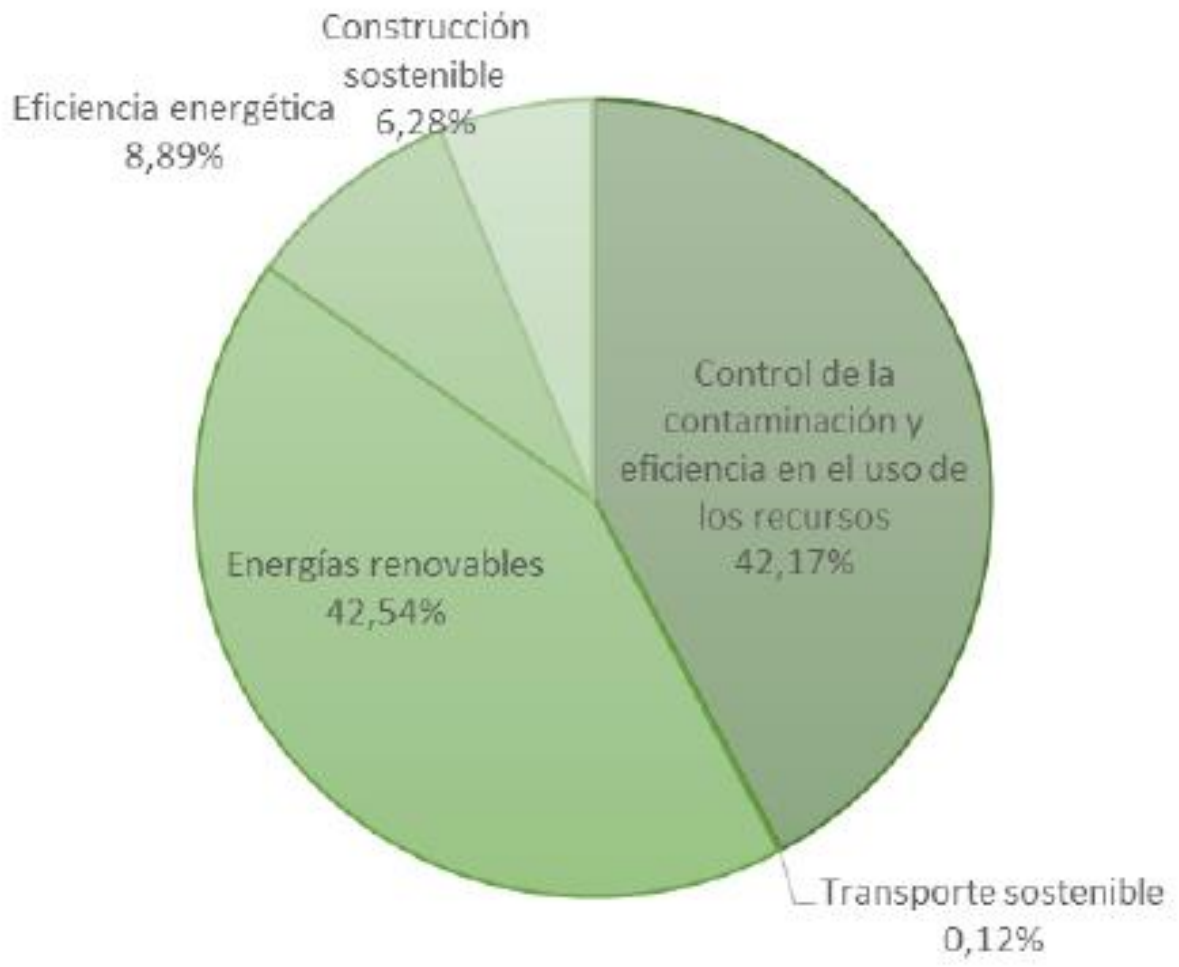

Figura 4. Distribución de la cartera de proyectos por criterios de elegibilidad [40] 
Para el año 2018, Bancoldex había efectuado desembolsos por 328,358 millones de pesos a través de 176 créditos, destinados a financiar 273 proyectos en 22 departamentos de Colombia (ver figura 6), beneficiando a 158 compañías, de las cuales alrededor de un $33 \%$ corresponden al segmento de pequeña y mediana empresa. El desembolso promedio fue de 1,868 millones por crédito, con un marco de tiempo promedio de 5.7 años por duración de proyecto. La figura 7 presenta la distribución de los 273 proyectos de acuerdo con los criterios de elegibilidad del programa de Bonos Verdes.

Algunas cifras notables relacionadas con el impacto causado por proyectos financiados mediante el programa de Bonos verdes de Bancoldex:

- $\quad$ 99,8 GWh de energía eléctrica generada por año a partir de fuentes renovables de forma gratuita a la red eléctrica del Sistema Interconectado Nacional.

- $\quad 788.277$ metros cúbicos de gas natural que se han dejado de utilizar como fuente de combustible fósil en diversos procesos.

- 360 toneladas anuales de carbón que han sido substituidas por otras fuentes de combustible (desechos orgánicos, biomasa, biogás, entre otros).

- 22.333 toneladas de dióxido de carbono que se han dejado de emitir por año.

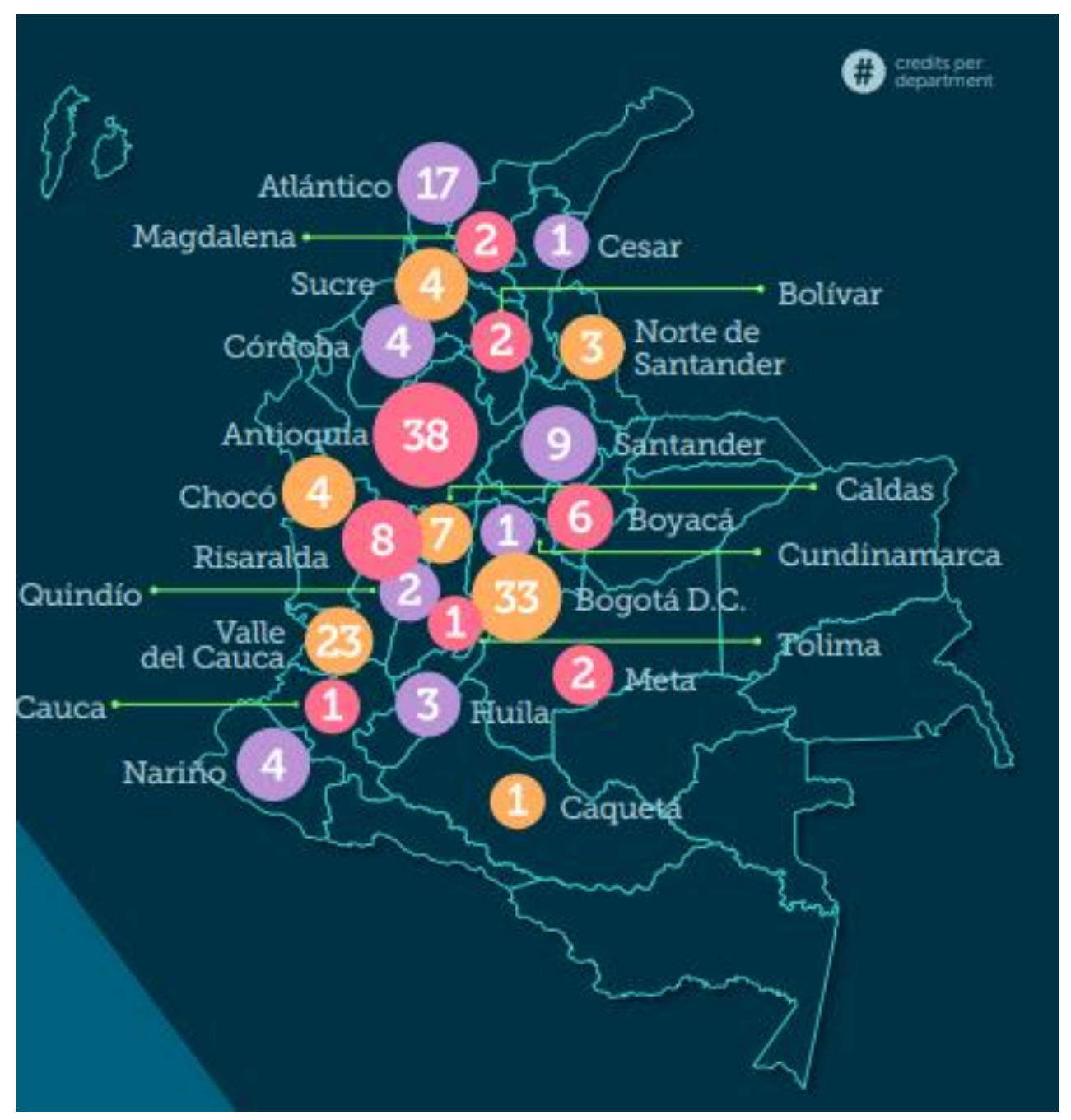

Figura 6. Número de créditos otorgados por región de Colombia [40] 


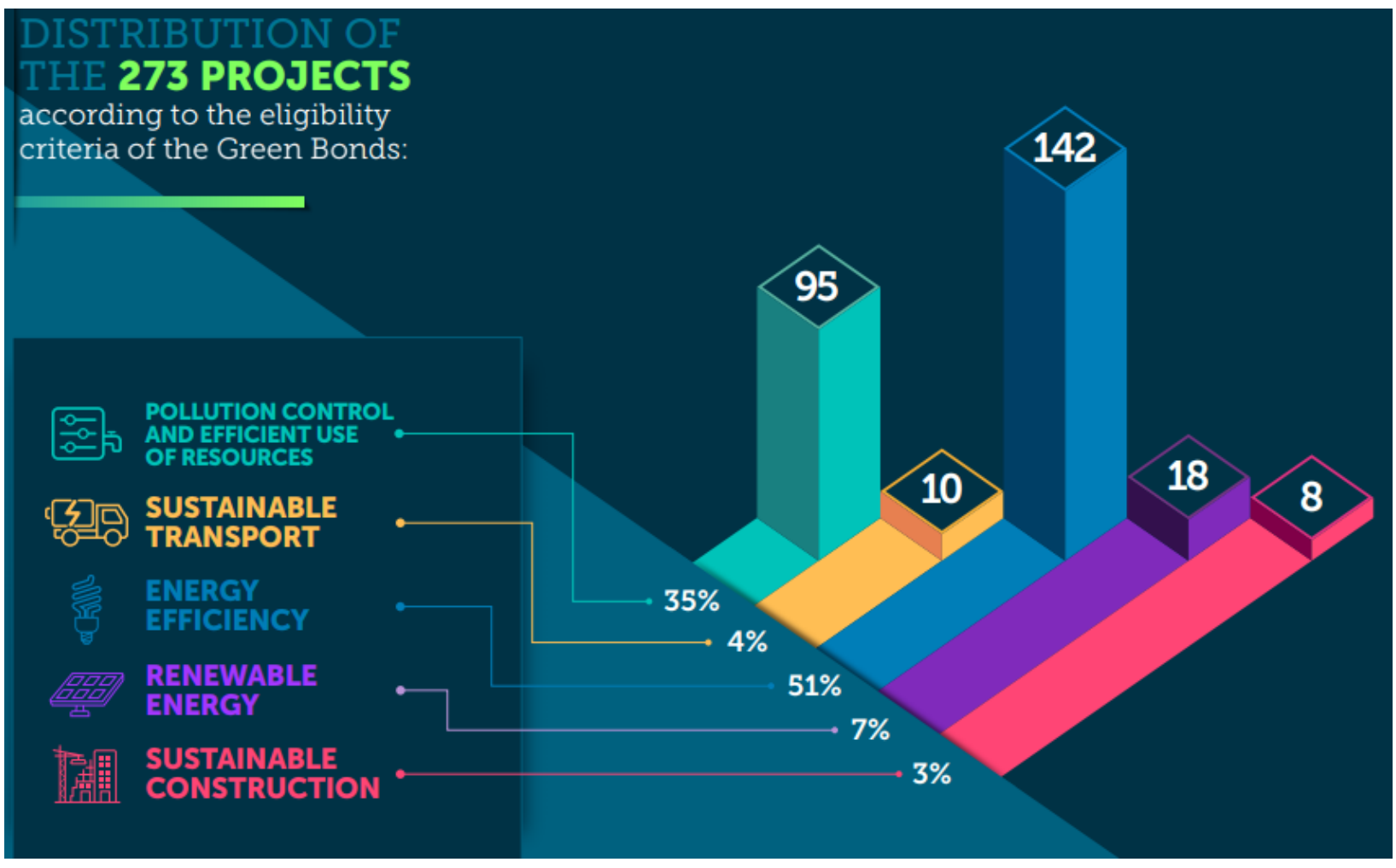

Figura 7. Distribución de los 273 proyectos de acuerdo a los criterios de elegibilidad del programa de Bonos Verdes [40]

\section{COMENTARIOS FINALES}

La propuesta para la apertura de línea de productos verdes en la banca colombiana busca que este sector financiero aumente tanto la captación como la colocación de sus recursos y el destino de estos, sea dado en proyectos que estén ligados con el bienestar social.

Con el presente trabajo se pretendió presentar un escenario, a modo de discusión propuesta, para que en la banca colombiana se realice la apertura de una nueva línea de negocio enfocada a ofrecer productos con inversión y destinación ecológica, lo cual también comprende el entendimiento y la apropiación de la importancia que tienen los proyectos verdes en el mundo actual, y cómo se podrían ver beneficiados con el apoyo a esta iniciativa, en temas de disminución de impuestos por la labor social que se desarrollaría.

Esto se podría lograr a través de la implementación de estrategias, cuya finalidad sea la captación de dinero de pequeños y grandes inversionistas, mediante la emisión de bonos verdes, los cuales generarían una tasa de interés más alta de la que se ofrece en el mercado convencional por productos similares, dichos recursos tendrán una destinación amigable con el medio ambiente.

Cuando se habla de la destinación amigable de recursos, se hace foco a la creación de una nueva línea de crédito que se oriente hacia el desarrollo de las finanzas verdes, donde la tasa de colocación sea más baja con relación a las demás líneas de crédito y así las personas se interesen en adquirir y apoyar este tipo de iniciativas sostenibles.

\section{REFERENCIAS}

[1] E. R. Zapa Pérez, «Impacto de la Gestión por Procesos en la Innovación de las Organizaciones», Rev. CINTEX, vol. 19, pp. 23-37, dic. 2014.

[2] E. A. Duque-Grisales, J. A. Patiño-Murillo, y L. D. Vélez-Gómez, «Aplicación del mercado de carbono en pequeñas centrales hidroeléctricas», Energética, vol. 44, pp. 19-32, 2014. 
[3] E. Duque, J. Patiño, y L. Vélez, «Implementation of the ACM0002 methodology in small hydropower plants in Colombia under the Clean Development Mechanism», Int. J. Renew. Energy Res., vol. 6, n. ${ }^{\circ}$, pp. 21-33, 2016.

[4] S. Ruiz, J. Patiño, A. Marquez-Ruiz, J. Espinosa, E. Duque, y P. Ortiz, «Optimal Design of a Diesel-PVWind-Battery-Hydro Pumped POWER system with the Integration of ELECTRIC vehicles in a Colombian Community», Energies, vol. 12, n. ${ }^{\circ} 23$, p. 4542, nov. 2019, doi: 10.3390/en12234542.

[5] E. Duque, J. González Ruiz, y J. Restrepo, «The Clean Development Mechanism as a Means to Assess the Kyoto Protocol in Colombia», Int. J. Renew. Energy Res., vol. 7, n. ${ }^{\circ}$ 3, pp. 1205-1212, 2017.

[6] E. A. Duque Grisales, J. Molina Flórez, y N. Ossa Núñez, «Operación del sistema de autocontrol y gestión del riesgo de lavado de activos y financiación del terrorismo en empresas del sector comercial», Rev. CINTEX, vol. 23, n. ${ }^{\circ} 1$, pp. 32-42, oct. 2018, doi: https://doi.org/10.33131/24222208.306.

[7] R. A. Arbeláez Pérez, E. A. Duque Grisales, y J. A. Patiño Murillo, «Relación de los principales mercados bursátiles durante y después de la crisis subprime con el mercado de renta variable colombiano», Mercatec, n. ${ }^{\circ}$ 55, pp. 14-24, 2018.

[8] J. Echavarría, "Condiciones Laborales y Productivas en Microempresas de Confección de la ciudad de Medellín», Rev. CINTEX, vol. 20, n. ², pp. 79-95, 2015.

[9] I. D. Rojas Arenas, «Del desarrollo económico al desarrollo económico endógeno: una mirada desde el pensamiento complejo», Rev. CINTEX, vol. 23, n. ${ }^{\circ}$ 1, pp. 12-23, oct. 2018, doi: 10.33131/24222208.308.

[10] J. A. Londoño-Gallego, S. M. Velásquez Restrepo, M. E. Villa Rodríguez, F. D. J. Franco Cuartas, y N. E. Viana-Rúa, "Identificación de tipos, modelos y mecanismos de transferencia tecnológica que apalancan la innovación", Rev. CINTEX, vol. 23, n. ${ }^{\circ} 2$, pp. 13-23, dic. 2018, doi: 10.33131/24222208.314.

[11] G. Lobos, O. Vallejos, C. Caroca, y C. Marchant, «El mercado de bonos de carbono (Bonos Verdes): Una Revisión», Rev. Interam. Ambiente Tur.-RIAT, vol. 1, n. ${ }^{\circ} 1$, pp. 42-52, ago. 2005, doi: 10.4067/riatvol1iss1pp42-52\%250718-235X.

[12] M. Y. el Morjani, «Valoración de instrumentos emergentes de financiación: Bonos verdes», Master thesis, Universitat Politecnica de Valencia, 2018.

[13] E. Abad Segura y M. del C. Valls Martínez, «Análisis de viabilidad de la banca ética en España a través de Triodos Bank. Comparativa económico-financiera con la banca tradicional», REVESCO Rev. Estud. Coop., vol. 128, n. ${ }^{\circ}$ 0, may 2018, doi: 10.5209/REVE.60205.

[14] A. Sánchez, F. Pérez-Sosa, y I. De Negocios, «La banca y la sustentabilidad: Una aproximación teórica (Banking and sustainability: A theoretical approach)», Innovaciones Negocios, vol. 13, pp. 145-163, 2016.

[15] A. Rojas Esquivel, «Alternativas para Incluir Aspectos Ambientales en el Sector Financiero», Centro Latinoamericano de Competitividad y Desarrollo Sostenible, Costa Rica, Documento de Trabajo CEN 772, 2003. [En línea]. Disponible en: http://x.incae.edu/EN/clacds/publicaciones/pdf/cen772.pdf.

[16] J. C. Fernández Hinojosa, «Los bonos verdes: el caso de Iberdrola», Universidad de Sevilla, Sevilla, España, 2018.

[17] S. Rovira, J. A. Patiño, y M. Schaper, «Ecoinnovación y producción verde: una revisión sobre las políticas de América Latina y el Caribe». CEPAL, 2017, [En línea]. Disponible en: https://repositorio.cepal.org/handle/11362/40968.

[18] B. M. Gaviria Montoya, J. L. Hincapié Vásquez, y M. C. Bermeo Giraldo, «Análisis comparativo de las alternativas de financiación para las PYMES en Antioquia», Rev. CIES, vol. 9, n. ${ }^{\circ}$ 01, pp. 164-176, 2018.

[19] E. A. Trujillo Niño, M. Gamba Plata, y L. M. Arenas Rojas, «Las dificultades de las Pymes en América Latina y Colombia para lograr ser competitivas y sostenibles», Universidad Jorge Tadeo Lozano, Bogotá, Colombia, 2016.

[20] F. Leal Medina, R. González Acolt, y B. García Martínez, «Financiamiento verde para pequeñas y medianas empresas. Caso de la industria manufacturera del municipio de Aguascalientes», en 
Investigaciones en la gestión de las ciencias administrativas, competitividad y finanzas, 1. ${ }^{a}$ ed., México, D.F.: Competitive Press, 2016, pp. 197-210.

[21] M. H. Badii, «Desarrollo sustentable: fundamentos, perspectivas y limitaciones», Innovaciones Negocios, vol. 1, n. ${ }^{\circ}$ 2, pp. 199-227, 2004.

[22] M. Chamochin, «El nexo entre finanzas, sostenibilidad y energía», Bie3 Bol. IEEE, n. ${ }^{\circ}$ 6, pp. 965-1004, 2017.

[23] A. Arenas, E. Escobar, J. D. Acosta, L. Monsalve, y E. D. Oyola Arcila, «Responsabilidad social empresarial ¿Moda o compromiso real?», Universidad de Medellín, Medellín, Colombia, 2012.

[24] N. Oliva Pérez, Impuestos verdes: ¿una alternativa viable para el Ecuador? Quito, Ecuador: Sevilla: Fundación Friedrich Ebert ILDIS : Centro de Estudios Fiscales CEF ; EcoEcoEs Asociación Ecológica en España, 2011.

[25] G. González Bermúdez, «Regulación jurídica de los incentivos económico- financieros para las Producciones más Limpias en Cuba», Bachelor, Universidad Central "Marta Abreu" de Las Villas, 2017.

[26] E. Duque Grisales y J. A. Patiño Murillo, «El mercado de bonos de carbono y su aplicación para proyectos hidroeléctricos», Rev. CINTEX, vol. 18, pp. 131-143, 2013.

[27] R. Martínez Castillo, «La importancia de la educación ambiental ante la problemática actual», Rev. Electrónica Educ., vol. 14, n. ${ }^{\circ} 1$, pp. 97-111, 2010.

[28] L. M. Echeverri, «Inserción Del Mercadeo Verde En Prácticas Empresariales En Colombia (Casos De Estudio) (Insertion of Green Marketing in Business Practices in Colombia (Case Studies))», Rev. Luna Azul, n. ${ }^{\circ} 31$, pp. 122-138, 2010.

[29] Plan Nacional de Negocios Verdes. Colombia: Ministerio de Ambiente y Desarrollo Sostenible, 2014.

[30] M. Mira, S. Kittel, A. Ospina, J. P. Bonilla, y M. Murcia, "GUÍA DE VERIFICACIÓN Y EVALUACIÓN DE CRITERIOS DE NEGOCIOS VERDES». Ministerio de Ambiente y Desarrollo Sostenible, ene. 2016, [En línea]. Disponible en: https://www.minambiente.gov.co/index.php/negocios-verdes-ysostenibles/negocios-verdes/criterios-para-identificar-los-bienes-y-servicios.

[31] «LAS EMPRESAS MÁS SOSTENIBLES DE COLOMBIA», Cecodes - Desarrollo Sostenible, sep. 20, 2016. https://www.cecodes.org.co/site/las-empresas-mas-sostenibles-colombia/\# (accedido ago. 15, 2019).

[32] «Bonos verdes: qué son y cómo funcionan», BBVA, oct. 06, 2017. https://www.bbva.com/es/bonosverdes-que-son-que-financian/ (accedido ago. 25, 2019).

[33] «Bonos Verdes: una forma de financiar proyectos sostenibles», Grupo Bancolombia - Sostenibilidad, 2020. https://www.grupobancolombia.com/wps/portal/acerca-de/informacioncorporativa/sostenibilidad/actualidad-sostenible/bonos-verdes-una-forma-de-financiar-proyectossostenibles?utm_source=contenido\&utm_medium=boton\&utm_campaign=campana-sostenibilidaddow-jon (accedido ago. 05, 2019).

[34] "Mercados Voluntarios de Carbono», ECODES - Cambio Climático, 2020. https://ecodes.org/cambioclimatico-y-ecodes/mercados-voluntarios-de-carbono\#.Xh9LHshKjIU (accedido ago. 05, 2019).

[35] «Negocios Verdes», CORANTIOQUIA, 2019. https://www.corantioquia.gov.co/Paginas/VerContenido.aspx?List=MenuSuperior\&item=168 (accedido ago. 04, 2019).

[36] D. Fernández, «El mercado de bonos se tiñe de verde», El País, España, feb. 18, 2018.

[37] "¿Qué son las líneas de financiamiento verde?», ASOBANCARIA - Saber Más Ser Más, 2019. https://www.sabermassermas.com/que-son-lineas-de-financiamiento-verde/ (accedido ago. 03, 2019).

[38] F. Piza, D. Arévalo, y J. Jacob, «PROTOCOLO VERDE: AGENDA DE COLABORACION ENTRE EL GOBIERNO NACIONAL Y EL SECTOR FINANCIERO COLOMBIANO». ASOBANCARIA, nov. 2017, [En línea]. Disponible en:

http://www.minambiente.gov.co/images/NegociosVerdesysostenible/pdf/criterios_negocios_verdes/c riterios_actualizado_2016/Guia_Verificaci\%C3\%B3n_Criterios_NV_V12_26_01_2016.pdf.

[39] «Green bond principles: Voluntary Process Guidelines for Issuing Green Bonds», ICMA, jun. 2018. Accedido: jun. 06, 2019. [En línea]. Disponible en: 
https://www.icmagroup.org/assets/documents/Regulatory/Green-Bonds/June-2018/Green-BondPrinciples---June-2018-140618-WEB.pdf.

[40] BANCOLDEX, «First Green Bonds Report», BANCOLDEX - BANCO DE COMERCIO EXTERIOR DE COLOMBIA, Bogotá, Colombia, 1, 2018. Accedido: jun. 07, 2019. [En línea]. Disponible en: https://www.bancoldex.com/sites/default/files/11097_green_bonds_report__bancoldex_2018_copy.pdf. 